\title{
Isotopic fractionation of carbon, deuterium, and nitrogen: a full chemical study ${ }^{\star}$
}

\author{
E. Roueff ${ }^{1,2}$, J. C. Loison ${ }^{3}$, and K. M. Hickson ${ }^{3}$ \\ 1 LERMA, Observatoire de Paris, PSL Research University, CNRS, UMR8112, Place Janssen, 92190 Meudon Cedex, France \\ e-mail: evelyne.roueff@obspm.fr \\ 2 Sorbonne Universités, UPMC Univ. Paris 6, 4 Place Jussieu, 75005 Paris, France \\ 3 ISM, Université de Bordeaux - CNRS, UMR 5255, 351 cours de la Libération, 33405 Talence Cedex, France \\ e-mail: jean-christophe.loison@u-bordeaux.fr
}

Received 6 October 2014 / Accepted 5 January 2015

ABSTRACT

\begin{abstract}
Context. The increased sensitivity and high spectral resolution of millimeter telescopes allow the detection of an increasing number of isotopically substituted molecules in the interstellar medium. The ${ }^{14} \mathrm{~N} /{ }^{15} \mathrm{~N}$ ratio is difficult to measure directly for molecules containing carbon.

Aims. Using a time-dependent gas-phase chemical model, we check the underlying hypothesis that the ${ }^{13} \mathrm{C} /{ }^{12} \mathrm{C}$ ratio of nitriles and isonitriles is equal to the elemental value.

Methods. We built a chemical network that contains D, ${ }^{13} \mathrm{C}$, and ${ }^{15} \mathrm{~N}$ molecular species after a careful check of the possible fractionation reactions at work in the gas phase.

Results. Model results obtained for two different physical conditions that correspond to a moderately dense cloud in an early evolutionary stage and a dense, depleted prestellar core tend to show that ammonia and its singly deuterated form are somewhat enriched in ${ }^{15} \mathrm{~N}$, which agrees with observations. The ${ }^{14} \mathrm{~N} /{ }^{15} \mathrm{~N}$ ratio in $\mathrm{N}_{2} \mathrm{H}^{+}$is found to be close to the elemental value, in contrast to previous models that obtain a significant enrichment, because we found that the fractionation reaction between ${ }^{15} \mathrm{~N}$ and $\mathrm{N}_{2} \mathrm{H}^{+}$has a barrier in the entrance channel. The high values of the $\mathrm{N}_{2} \mathrm{H}^{+} /{ }^{15} \mathrm{NNH}^{+}$and $\mathrm{N}_{2} \mathrm{H}^{+} / \mathrm{N}^{15} \mathrm{NH}^{+}$ratios derived in $\mathrm{L} 1544$ cannot be reproduced in our model. Finally, we find that nitriles and isonitriles are in fact significantly depleted in ${ }^{13} \mathrm{C}$, thereby challenging previous interpretations of observed $\mathrm{C}^{15} \mathrm{~N}, \mathrm{HC}^{15} \mathrm{~N}$, and $\mathrm{H}^{15} \mathrm{NC}$ abundances from ${ }^{13} \mathrm{C}$ containing isotopologues
\end{abstract}

Key words. astrochemistry - molecular processes - ISM: molecules - ISM: clouds

\section{Introduction}

Understanding isotopic abundances on a large scale is a major goal that has received a great deal of attention for its application to terrestrial environments (ocean, meteorites), the solar system (planets, comets), and galactic interstellar space. The variation in isotopic ratios may give us some information about the link between solar system objects and galactic interstellar environments as discussed by Aléon (2010). We mainly focus our study on interstellar environments where low-temperature conditions may significantly affect the isotopic ratios of the molecular content. Isotopic molecules are detected in a variety of environments and offer an additional tool for determining physical conditions because they usually do not suffer from opacity problems.

Early modeling studies of ${ }^{13} \mathrm{C}$ and ${ }^{18} \mathrm{O}$ isotopic enrichment were performed by Langer et al. (1984), who introduced different isotopic exchange reactions, relying on previous theoretical and experimental studies by Watson et al. (1976) and Smith \& Adams (1980). The possible effects of selective photodissociation of CO have subsequently been emphasized (Glassgold et al. 1985; Le Bourlot et al. 1993; Visser et al. 2009), which tend to increase the $\mathrm{CO} /{ }^{13} \mathrm{CO}$ ratio. The use of the $\mathrm{CN}$ radical as a tracer of ${ }^{12} \mathrm{C} /{ }^{13} \mathrm{C}$ isotopic ratio has been raised by Savage et al. (2002), Milam et al. (2005), who studied the corresponding gradient as a

$\star$ Appendices are available in electronic form at http: //wwW . aanda.org function of the galactic distance. The actual value of the ${ }^{12} \mathrm{C} /{ }^{13} \mathrm{C}$ isotopic ratio in the local interstellar medium (ISM) is assumed to be 68 (Milam et al. 2005).

The possibility of nitrogen isotopic fractionation in interstellar clouds has been investigated by Terzieva \& Herbst (2000), who suggest various ${ }^{15} \mathrm{~N}$ isotopic exchange reactions. Rodgers \& Charnley (2004, 2008a,b) used these suggested reaction-rate constants to predict nitrogen isotopic fractionation in chemical models of dense interstellar molecular cores. They specifically discussed the role of the atomic-to-molecular nitrogen ratio in the fractionation process and the possible link between nitrogen hydrides and $\mathrm{CN}$ containing molecules (nitriles). The corresponding observations are sparse, however, and difficult because the elemental ${ }^{14} \mathrm{~N} /{ }^{15} \mathrm{~N}$ ratio is high $(441 \pm 5)$, as determined by the recent Genesis solar wind sampling measurement (Marty et al. 2011), and is assumed to hold in the local ISM.

In addition, the zero point energy (ZPE) differences involved in nitrogen fractionation reactions are small, and the predicted corresponding chemical enrichment is moderate. Lucas \& Liszt (1998) report $\mathrm{HC}^{15} \mathrm{~N}$ absorption in diffuse clouds located in front of distant quasars with a $\mathrm{HCN} / \mathrm{HC}^{15} \mathrm{~N}$ ratio of $270 \pm 27$, close to value reported for the Earth. However, various new observations of isotopic nitrogen containing molecules have been reported, including ${ }^{15} \mathrm{~N}$ substituted ammonia and deuterated ammonia (Gerin et al. 2009; Lis et al. 2010), the diazenylium ion $\left(\mathrm{N}_{2} \mathrm{H}^{+}\right.$; Bizzocchi et al. 2010, 2013; Daniel et al. 2014), $\mathrm{CN}$ and 
HCN (Ikeda et al. 2002; Pillai et al. 2007; Adande \& Ziurys 2012; Hily-Blant et al. 2013b; Daniel et al. 2014), HCN and HNC (Wampfler et al. 2014). The strong depletion found in ${ }^{15} \mathrm{~N}$ variants of the $\mathrm{N}_{2} \mathrm{H}^{+}$isotopologue strongly contradicts model predictions (Gerin et al. 2009), which motivates a reinvestigation of the chemical processes at work. With this in mind, the link between deuterated chemistry and the possible role of ortho/para molecular hydrogen has been studied by Wirström et al. (2012).

We analyze in Sect. 2 the various possible isotopic exchange reactions that are involved for molecules containing carbon and nitrogen. Indeed, most nitrogen-fractionation observational results for $\mathrm{CN}$-containing molecules involve only ${ }^{13} \mathrm{C}$ and ${ }^{15} \mathrm{~N}$ species so that the measure of the nitrogen isotopic ratio assumes a fixed ${ }^{12} \mathrm{C} /{ }^{13} \mathrm{C}$ fraction. We examine and extend the pioneering study of Terzieva \& Herbst (2000) and check for the possible presence of barriers in the entrance channels of isotopic exchange reactions through theoretical calculations. We also update the ZPE values involved and derive the corresponding exothermicity values. We present our new chemical model in Sect. 3 and compare it with available observations and other models. Our conclusions are presented in Sect. 5.

\section{Chemical reactions involving isotopic substitutes of ${ }^{12} \mathrm{C}$ and ${ }^{14} \mathrm{~N}$}

\section{1. ${ }^{13} \mathrm{C}$ and ${ }^{15} \mathrm{~N}$ exchange reactions}

At very low temperatures, isotopic exchange reactions may only occur if no barrier is present between the interacting atoms, ions, and molecules or if tunnelling plays an important role. Experimental information is crucial, and we constrain the evaluation of rate constants using that information. If no experimental data are available, we apply theoretical methods to determine the presence of a barrier: A first technique uses density functional theory (DFT) calculations with the hybrid M06-2X functional developed by Zhao \& Truhlar (2008), which is well suited to thermochemical calculations, associated to the cc-pVTZ basis set using GAUSSIAN09 software. The alternative is provided by the MRCI+Q method (with the aug-cc-pVTZ basis set). For barrierless cases, we derive the reaction rate constants by using a simple capture theory (Georgievskii \& Klippenstein 2005) for both ion-neutral and neutral-neutral reactions. We consider four different families of isotopic exchange reactions:

- A: direct reactions. The proton transfer in the $\mathrm{N}_{2} \mathrm{H}^{+}+$ $\mathrm{N}^{15} \mathrm{~N} \rightarrow \mathrm{N}^{15} \mathrm{NH}^{+}+\mathrm{N}_{2}$ reaction can serve as an example. In this case and for reactions without a barrier, the reaction rate coefficient of the forward reaction is equal to the capture-rate constant multiplied by a probability factor $f(B, M), f(B, M)$ depending on the rotational constant, mass, and symmetry values of the reactants and products. In reactions involving ${ }^{15} \mathrm{~N}$ and ${ }^{13} \mathrm{C}$, the mass ratio of reactants and products are very close, and $f(B, M) \cong \sigma_{\text {entrance channel }} / \sigma_{\text {exit channels. }}$ (The symmetry number $\sigma$ is equal to the number of pathways.) The reverse reaction is calculated from the equilibrium constant $K$, as in Terzieva \& Herbst (2000): $K=k_{\mathrm{f}} / k_{\mathrm{r}}=$ $f(B, M) \times \exp (\Delta E / k T)$.

- $B$ : reactions involving adduct formation and leading to direct products without isomerization. As an example, we refer to ${ }^{15} \mathrm{~N}^{+}+\mathrm{N}_{2} \rightarrow \mathrm{N}^{15} \mathrm{~N}+{ }^{14} \mathrm{~N}^{+}$. We first assume that the high pressure rate constant is equal to the capture rate constant (for reactions without a barrier). We apply statistical theory for the system at thermal equilibrium so that $k_{\mathrm{f}}+k_{\mathrm{r}}=k_{\text {capture }}$. From the equilibrium constant expression, we then derive $k_{\mathrm{f}}=k_{\text {capture }} \times \frac{f(B, M)}{[f(B, M)+\exp (-\Delta E / k T)]}$ and $k_{\mathrm{r}}=k_{\text {capture }} \times \frac{\exp (-\Delta E / k T)}{[f(B, M)+\exp (-\Delta E / k T)]}$.

- $C$ : reactions involving adduct formation with isomerization pathways. Such a case holds for ${ }^{13} \mathrm{C}+\mathrm{HCN} \rightarrow{ }^{12} \mathrm{C}+\mathrm{H}^{13} \mathrm{CN}$. We again assume that the high pressure rate constant is given by capture theory (for reactions without a barrier). The isotopic isomerization reaction competes with the dissociation of the adduct. The rate constant depends on the location of the transition state, and statistical calculations are generally required to estimate the isomerization reaction rate constant. - D: other reactive exothermic channels. The exchange reaction is generally discarded. (The possibility of $\mathrm{N}$ atom exchange in the ${ }^{15} \mathrm{~N}+\mathrm{CN}$ and in ${ }^{15} \mathrm{~N}+\mathrm{C}_{2} \mathrm{~N}$ reactions is discussed.)

The knowledge of the exoergicity values $\Delta E$ is also a major concern. They are obtained from the differences of the ZPEs between products and reactants. We recall the corresponding expressions in Appendix B and derive their values by using the most recent determinations of spectroscopic constants reported in Tables B.2-B.4.

We summarize in Table 1 the different isotopic exchange reactions considered and display the corresponding reaction rate constants. Detailed information is provided in Appendix A on the theoretical methods used for the different systems. The reactions involving ${ }^{15} \mathrm{~N}$ are displayed in the upper part of the table. We also consider ${ }^{13} \mathrm{C}$ isotopic exchange reactions in the lower part of Table 1. Table 1 shows two main discrepancies compared to previous studies by Terzieva \& Herbst (2000). The exchange reactions between atomic ${ }^{15} \mathrm{~N}$ and $\mathrm{N}_{2} \mathrm{H}^{+}$as well as with $\mathrm{HCNH}^{+}$are found to be unlikely to occur because significant barriers arise in the complex formation step. A similar result is obtained for ${ }^{15} \mathrm{~N}^{+}$exchange with $\mathrm{NO}$, whereas these reactions had been included in Terzieva \& Herbst (2000). The exchange reaction between atomic ${ }^{15} \mathrm{~N}$ and $\mathrm{CN}$, which was suggested by Rodgers \& Charnley (2008a), is found to be plausible. Additional exchange possibilities have also been considered, such as the reaction between ${ }^{15} \mathrm{~N}$ and $\mathrm{C}_{2} \mathrm{~N}$. As far as ${ }^{13} \mathrm{C}$ possible fractionation is concerned, we find that $\mathrm{CN}$ could be enriched in ${ }^{13} \mathrm{C}$ through the exchange reactions of $\mathrm{CN}$ with ${ }^{13} \mathrm{C}$ and ${ }^{13} \mathrm{C}^{+}$. However, such a mechanism does not hold for HNC because atomic carbon is found to react with HNC (Loison et al. 2014). ${ }^{13} \mathrm{C}$ enrichment of HCN is also found to be unlikely since the calculated transition state lies above the entrance level in the hypothetical isomerization process ( $\mathrm{C}$ mechanism).

\subsection{Ammonia synthesis}

Ammonia synthesis proceeds mainly through a chain of reactions starting with ${ }^{14} \mathrm{~N}^{+}$and $\mathrm{H}_{2}$, because the reaction between $\mathrm{N}$ and $\mathrm{H}_{3}{ }^{+}$has been shown to be inefficient (Milligan et al. 2000).

\subsubsection{The ${ }^{14} \mathrm{~N}^{+}+\mathrm{H}_{2}$ reaction and isotopic substitutions}

This almost thermoneutral reaction deserves a special mention and has received considerable attention. Le Bourlot (1991) first pointed out the possible role of ortho- $\mathrm{H}_{2}$ in the interstellar chemistry of ammonia based on the energy of its $J=1$ rotational level almost compensating for the small endothermicity of the reaction ${ }^{14} \mathrm{~N}^{+}+\mathrm{H}_{2} \rightarrow \mathrm{NH}^{+}+\mathrm{H}$. Dislaire et al. (2012) subsequently reanalyzed the experimental data (Marquette et al. 1988) and suggest new separate expressions for the reaction rate with $\mathrm{p}-\mathrm{H}_{2}$ 
Table 1. Isotopic exchange reactions.

\begin{tabular}{|c|c|c|c|c|c|c|}
\hline Label/ & \multicolumn{3}{|c|}{ Reaction } & $k_{\mathrm{f}}^{*}$ & $f(B, M)^{*}$ & $\Delta E^{*}$ \\
\hline (1) $\mathrm{A}$ & $\mathbf{N}^{15} \mathbf{N}+\mathbf{N}_{2} \mathbf{H}^{+}$ & $\rightleftharpoons$ & $\mathbf{N}^{15} \mathbf{N H}^{+}+\mathbf{N}_{2}$ & $2.3 \times 10^{-10}$ & 0.5 & 10.3 \\
\hline (2) $\mathrm{A}$ & $\mathbf{N}^{15} \mathbf{N}+\mathbf{N}_{2} \mathbf{H}^{+}$ & $\rightleftharpoons$ & ${ }^{15} \mathbf{N N H}^{+}+\mathbf{N}_{2}$ & $2.3 \times 10^{-10}$ & 0.5 & 2.1 \\
\hline (3) $\mathrm{A}$ & $\mathbf{N}^{15} \mathbf{N}+{ }^{15} \mathbf{N N H}^{+}$ & $\rightleftharpoons$ & $\mathbf{N}^{15} \mathbf{N H}^{+}+\mathbf{N}^{15} \mathbf{N}$ & $4.6 \times 10^{-10}$ & 1 & 8.1 \\
\hline (4) B & ${ }^{15} \mathbf{N}^{+}+\mathbf{N}_{2}$ & $\rightleftharpoons$ & ${ }^{14} \mathbf{N}^{+}+\mathbf{N}^{15} \mathbf{N}$ & $4.8 \times 10^{-10} \times \frac{2}{2+\exp (-28.3 / T)}$ & 2 & 28.3 \\
\hline (5) $\mathrm{C}$ & ${ }^{15} \mathbf{N}+\mathbf{C N C}^{+}$ & $\rightleftharpoons$ & $\mathbf{C}^{15} \mathbf{N C}^{+}+{ }^{14} \mathbf{N}$ & $3.8 \times 10^{-12} \times\left(\frac{T}{300}\right)^{-1}$ & 1 & 38.1 \\
\hline (6) $\mathrm{D}$ & ${ }^{15} \mathbf{N}^{+}+{ }^{14} \mathbf{N O}$ & $\rightleftharpoons$ & ${ }^{14} \mathbf{N}^{+}+{ }^{15} \mathbf{N O}$ & no react & - & 24.3 \\
\hline (7) barrier & ${ }^{15} \mathbf{N}+\mathbf{N}_{2} \mathbf{H}^{+}$ & $\rightleftharpoons$ & ${ }^{14} \mathbf{N}+\mathbf{N}^{15} \mathbf{N H}^{+}$ & no react & - & 38.5 \\
\hline (8) barrier & ${ }^{15} \mathbf{N}+\mathbf{N}_{2} \mathbf{H}^{+}$ & $\rightleftharpoons$ & ${ }^{14} \mathbf{N}+{ }^{15} \mathbf{N N H}^{+}$ & no react & - & 30.4 \\
\hline (9) barrier & ${ }^{15} \mathbf{N N H}^{+}+\mathbf{H}$ & $\rightleftharpoons$ & $\mathbf{H}+\mathbf{N}^{15} \mathbf{N H}^{+}$ & no react & - & 8.1 \\
\hline (10) barrier & ${ }^{15} \mathbf{N}+\mathbf{H C N H}^{+}$ & $\rightleftharpoons$ & ${ }^{14} \mathbf{N}+\mathbf{H} \mathbf{C}^{15} \mathbf{N H}^{+}$ & no react & - & 37.1 \\
\hline (11) D & ${ }^{15} \mathbf{N}+\mathbf{C N}$ & $\rightleftharpoons$ & ${ }^{14} \mathbf{N}+\mathbf{C}^{15} \mathbf{N}$ & $\begin{array}{l}\text { upper limit : } 2.0 \times 10^{-10} \times \\
(T / 300)^{1 / 6} \times \frac{1}{1+\exp (-22.9 / T)}\end{array}$ & 1 & 22.9 \\
\hline (12) B & ${ }^{15} \mathbf{N}+\mathbf{C}_{2} \mathbf{N}$ & $\rightleftharpoons$ & ${ }^{14} \mathbf{N}+\mathbf{C}_{2}{ }^{15} \mathbf{N}$ & $\begin{array}{l}1.6 \times 10^{-10} \times(T / 300)^{1 / 6} \times \\
\frac{1}{1+\exp (-26.7 / \mathbf{T})}\end{array}$ & 1 & 26.7 \\
\hline (13) D & ${ }^{15} \mathbf{N}+{ }^{14} \mathbf{N O}$ & $\rightleftharpoons$ & ${ }^{14} \mathbf{N}+{ }^{15} \mathbf{N O}$ & - & - & 24.3 \\
\hline (14) B & ${ }^{13} \mathbf{C}^{+}+\mathbf{C O}$ & $\rightleftharpoons$ & ${ }^{12} \mathbf{C}^{+}+{ }^{13} \mathbf{C O}$ & $\begin{array}{l}6.6 \times 10^{-10} \times(T / 300)^{-0.45} \\
\times \exp (-6.5 / T) \times \frac{1}{1+\exp (-34.7 / T)}\end{array}$ & 1 & 34.7 \\
\hline (15) $\mathrm{A}$ & ${ }^{13} \mathrm{CO}+\mathrm{HCO}^{+}$ & $\rightleftharpoons$ & $\mathrm{CO}+\mathrm{H}^{13} \mathrm{CO}^{+}$ & $2.6 \times 10^{-10} \times(T / 300)^{-0.4}$ & 1 & 17.4 \\
\hline (16) B & ${ }^{13} \mathbf{C}^{+}+\mathbf{C N}$ & $\rightleftharpoons$ & ${ }^{12} \mathbf{C}^{+}+{ }^{13} \mathbf{C N}$ & $\begin{array}{l}3.82 \times 10^{-9} \times(T / 300)^{-0.4} \\
\times \frac{1}{1+\exp (-31.1 / T)}\end{array}$ & 1 & 31.1 \\
\hline (17) B & ${ }^{13} \mathbf{C}+\mathbf{C N}$ & $\rightleftharpoons$ & ${ }^{12} \mathbf{C}+{ }^{13} \mathbf{C N}$ & $3.0 \times 10^{-10} \times \frac{1}{1+\exp (-31.1 / T)}$ & 1 & 31.1 \\
\hline (18) $\mathrm{C}$ & ${ }^{13} \mathrm{C}+\mathbf{H C N}$ & $\rightleftharpoons$ & ${ }^{12} \mathbf{C}+\mathbf{H}^{13} \mathbf{C N}$ & no react & - & 48.4 \\
\hline (19) B & ${ }^{13} \mathbf{C}+\mathbf{C}_{2}$ & $\rightleftharpoons$ & ${ }^{12} \mathbf{C}+{ }^{13} \mathbf{C C}$ & $3.0 \times 10^{-10} \times \frac{2}{2+\exp (-26.4 / T)}$ & 2 & 26.4 \\
\hline (19) barrier & ${ }^{13} \mathrm{CH}+\mathbf{C O}$ & $\rightleftharpoons$ & ${ }^{13} \mathrm{CO}+\mathbf{C H}$ & no react & - & 28.6 \\
\hline
\end{tabular}

Notes. ${ }^{(*)} k_{\mathrm{f}}$ is the forward reaction rate coefficient. The reverse reaction rate coefficient, $k_{\mathrm{r}}$, is obtained by $k_{\mathrm{r}}=\frac{k_{\mathrm{f}}}{f(B, M)} \exp (-\Delta E / T)$.

Table 2. Reaction rate coefficients of $\mathrm{N}^{+}+\mathrm{H}_{2}$ and isotopic variants.

\begin{tabular}{llllc}
\hline \hline \multicolumn{3}{c}{ Reaction } & $k\left(\mathrm{~cm}^{3} \mathrm{~s}^{-1}\right)$ & Comment \\
\hline${ }^{14} \mathbf{N}^{+}+\mathrm{p}-\mathbf{H}_{2}$ & $\rightarrow$ & $\mathbf{N H}^{+}+\mathbf{H}$ & $8.35 \times 10^{-10} \times \exp (-168.5 / T)$ & Dislaire et al. (2012) \\
${ }^{14} \mathbf{N}^{+}+\mathbf{0}-\mathbf{H}_{2}$ & $\rightarrow$ & $\mathbf{N H}^{+}+\mathbf{H}$ & $4.2 \times 10^{-10} \times(T / 300)^{-0.17} \times \exp (-44.5 / T)$ & Dislaire et al. (2012) \\
${ }^{15} \mathbf{N}^{+}+\mathrm{p}-\mathbf{H}_{2}$ & $\rightarrow$ & ${ }^{15} \mathbf{N H}^{+}+\mathbf{H}$ & $8.35 \times 10^{-10} \times \exp (-164.3 / T)$ & see text \\
${ }^{15} \mathbf{N}^{+}+\mathbf{o}-\mathbf{H}_{2}$ & $\rightarrow$ & ${ }^{15} \mathbf{N H}^{+}+\mathbf{H}$ & $4.2 \times 10^{-10} \times(T / 300)^{-0.17} \times \exp (-39.7 / T)$ & see text \\
${ }^{14} \mathbf{N}^{+}+\mathbf{H D}$ & $\rightarrow$ & $\mathbf{N D}^{+}+\mathbf{H}$ & $3.17 \times 10^{-10} \times \exp (-16.3 / T)$ & Marquette et al. (1988) \\
${ }^{14} \mathbf{N}^{+}+\mathbf{H D}$ & $\rightarrow$ & $\mathbf{N H}^{+}+\mathbf{D}$ & $3.17 \times 10^{-10} \times \exp (-594.3 / T)$ & see text \\
${ }^{15} \mathbf{N}^{+}+\mathbf{H D}$ & $\rightarrow$ & ${ }^{15} \mathbf{N D}^{+}+\mathbf{H}$ & $3.17 \times 10^{-10} \times \exp (-9.3 / T)$ & see text \\
${ }^{15} \mathbf{N}^{+}+\mathbf{H D}$ & $\rightarrow$ & ${ }^{15} \mathbf{N H}^{+}+\mathbf{D}$ & $3.17 \times 10^{-10} \times \exp (-589.5 / T)$ & see text \\
${ }^{14} \mathbf{N}^{+}+\mathbf{D}_{2}$ & $\rightarrow$ & $\mathbf{N D}^{+}+\mathbf{D}$ & $2.37 \times 10^{-10} \times \exp (-197.9 / T)$ & Marquette et al. (1988) \\
${ }^{15} \mathbf{N}^{+}+\mathbf{D}_{2}$ & $\rightarrow$ & ${ }^{15} \mathbf{N D}^{+}+\mathbf{D}$ & $2.37 \times 10^{-10} \times \exp (-190.9 / T)$ & Marquette et al. (1988) \\
\hline
\end{tabular}

and o- $\mathrm{H}_{2}$. Similar results were obtained by Zymak et al. (2013), who also emphasized the possible role of the fine structure level of ${ }^{14} \mathrm{~N}^{+}$. We follow the prescription derived by Dislaire et al. (2012) and extend their analysis to deuterated forms and those including ${ }^{15} \mathrm{~N}$, as displayed in Table 2 . In the case of ${ }^{15} \mathrm{~N}$ substituted compounds, we have taken the (small) additional term due to the change in ZPE into account. These expressions should be used with caution because in their kinetic expression, we consider that the exponential term represents the enthalpy difference between the products and reactants. The capture rate constant of ${ }^{15} \mathrm{~N}^{+}+$HD reaction is about $(2 / 3)^{0.5}$ less than the rate of the ${ }^{15} \mathrm{~N}^{+}+\mathrm{H}_{2}$ reaction, owing to the different mass dependences. The formation of ${ }^{15} \mathrm{ND}^{+}$is favored at low temperatures.

\subsection{2. $\mathrm{NH}_{3}^{+}+\mathrm{H}_{2}$}

The final step of ion-molecule reactions leading to ammonia formation is the reaction between $\mathrm{NH}_{3}^{+}$and $\mathrm{H}_{2}$, giving $\mathrm{NH}_{4}^{+}$.
Although exothermic, this reaction has a strong temperature dependence, displaying a minimum at $T \sim 100 \mathrm{~K}$ and a slow increase at lower temperatures (Barlow \& Dunn 1987), which is interpreted by the presence of a barrier to complex formation, as discussed in Herbst et al. (1991). At temperatures close to $10 \mathrm{~K}$, the reaction is likely to proceed through tunneling that may take place or $\mathrm{H}$ atom abstraction. However, the $\mathrm{NH}_{3}^{+}$reaction with $\mathrm{D}_{2}$ is found to be slower when the temperature decreases because tunneling is not efficient with deuterium. We thus reconsider the isotopic variants of this reaction, as shown in Table 3, where we give the present reaction rates compared to previous values derived from Anicich \& Huntress (1986). These values are indeed different from those used in our previous studies (Roueff et al. 2005) where we assumed the same rate for the channels resulting from the reactions of $\mathrm{NH}_{3}^{+}$and isotopologues with $\mathrm{HD}$, based on pure statistical considerations. We discuss the resulting modifications in Sect. 3. Identical reaction rate coefficients are used for the ${ }^{15} \mathrm{~N}$ isotopically substituted reactions. 
Table 3. Reaction rate coefficients of $\mathrm{NH}_{3}^{+}+\mathrm{H}_{2}$ and isotopic variants at $T=10 \mathrm{~K}$.

\begin{tabular}{|c|c|c|c|c|}
\hline \multicolumn{3}{|c|}{ Reaction } & \multicolumn{2}{|c|}{$k\left(\mathrm{~cm}^{3} \mathrm{~s}^{-1}\right)$} \\
\hline & & & present work & old value $(*)$ \\
\hline $\mathbf{N H}_{3}^{+}+\mathbf{H}_{2}$ & $\rightarrow$ & $\mathbf{N H}_{4}^{+}+\mathbf{H}$ & $8.2 \times 10^{-13}$ & $2.4 \times 10^{-12}$ \\
\hline $\mathbf{N H}_{3}^{+}+\mathbf{H D}$ & $\rightarrow$ & $\mathbf{N H}_{4}^{+}+\mathbf{D}$ & $8.2 \times 10^{-13}$ & $1.2 \times 10^{-12}$ \\
\hline $\mathbf{N H}_{3}^{+}+\mathbf{H D}$ & $\rightarrow$ & $\mathbf{N H}_{3} \mathbf{D}^{+}+\mathbf{H}$ & $1.0 \times 10^{-13}$ & $1.2 \times 10^{-12}$ \\
\hline $\mathbf{N H}_{3}^{+}+\mathbf{D}_{2}$ & $\rightarrow$ & $\mathbf{N H}_{3} \mathbf{D}^{+}+\mathbf{D}$ & $1.0 \times 10^{-13}$ & $2.4 \times 10^{-12}$ \\
\hline $\mathbf{N H}_{2} \mathbf{D}^{+}+\mathbf{H}_{2}$ & $\rightarrow$ & $\mathbf{N H}_{3} \mathbf{D}^{+}+\mathbf{H}$ & $8.2 \times 10^{-13}$ & $2.4 \times 10^{-12}$ \\
\hline $\mathbf{N H}_{2} \mathbf{D}^{+}+\mathbf{H D}$ & $\rightarrow$ & $\mathbf{N H}_{3} \mathbf{D}^{+}+\mathbf{D}$ & $8.2 \times 10^{-13}$ & $1.2 \times 10^{-12}$ \\
\hline $\mathbf{N H}_{2} \mathbf{D}^{+}+\mathbf{H D}$ & $\rightarrow$ & $\mathbf{N H}_{2} \mathbf{D}_{2}^{+}+\mathbf{H}$ & $1.0 \times 10^{-13}$ & $1.2 \times 10^{-12}$ \\
\hline $\mathbf{N H}_{2} \mathbf{D}^{+}+\mathbf{D}_{2}$ & $\rightarrow$ & 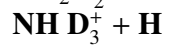 & $1.0 \times 10^{-13}$ & $2.4 \times 10^{-12}$ \\
\hline $\mathbf{N H D}_{2}^{+}+\mathbf{H}_{2}$ & $\rightarrow$ & $\mathbf{N H}_{2} \mathbf{D}_{2}^{+}+\mathbf{H}$ & $8.2 \times 10^{-13}$ & $2.4 \times 10^{-12}$ \\
\hline $\mathbf{N H D}_{2}^{+}+\mathbf{H D}$ & $\rightarrow$ & $\mathbf{N H}_{2} \mathbf{D}_{2}^{+}+\mathbf{D}$ & $8.2 \times 10^{-13}$ & $1.2 \times 10^{-12}$ \\
\hline $\mathbf{N H D}_{2}^{+}+\mathbf{H D}$ & $\rightarrow$ &  & $1.0 \times 10^{-13}$ & $1.2 \times 10^{-12}$ \\
\hline $\mathbf{N H D}_{2}^{+}+\mathbf{D}_{2}$ & $\rightarrow$ & $\mathbf{N H} \mathbf{D}_{3}^{+}+\mathbf{D}$ & $1.0 \times 10^{-13}$ & $2.4 \times 10^{-12}$ \\
\hline $\mathbf{N D}_{3}^{+}+\mathbf{H}_{2}$ & $\rightarrow$ & $\mathbf{N H} \mathbf{D}_{3}^{+}+\mathbf{H}$ & $8.2 \times 10^{-13}$ & $2.4 \times 10^{-12}$ \\
\hline $\mathbf{N D}_{3}^{+}+\mathbf{H D}$ & $\rightarrow$ & $\mathbf{N H} \mathbf{D}_{3}^{+}+\mathbf{D}$ & $8.2 \times 10^{-13}$ & $1.2 \times 10^{-12}$ \\
\hline $\mathbf{N D}_{3}^{+}+\mathbf{H D}$ & $\rightarrow$ & $\mathbf{N D}_{4}^{+}+\mathbf{H}$ & $1.0 \times 10^{-13}$ & $1.2 \times 10^{-12}$ \\
\hline $\mathbf{N D}_{3}^{+}+\mathbf{D}_{2}$ & $\rightarrow$ & $\mathbf{N D}_{4}^{+}+\mathbf{D}$ & $1.0 \times 10^{-13}$ & $2.4 \times 10^{-12}$ \\
\hline
\end{tabular}

References. $(*)$ Roueff et al. (2005).

\section{Models}

\subsection{General features}

Chemical reactions involving nitrogen atoms and $\mathrm{CH}, \mathrm{CN}$, and $\mathrm{OH}$ have been studied experimentally and shown to be less efficient than previously thought at low temperatures (Daranlot et al. 2012, 2013), which was confirmed by theoretical studies. The corresponding reaction rate constants have been implemented in the KIDA chemical data base (Wakelam et al. 2013), and we updated our chemical network accordingly. We also include the reactions discussed in Loison et al. (2014) in their study of $\mathrm{HCN} / \mathrm{HNC}$ chemistry. We explicitly include deuterium, ${ }^{13} \mathrm{C}$, and ${ }^{15} \mathrm{~N}$ molecular compounds in our chemical network. The reactions displayed in Table 1, have been included, which allows us to test the hypothesis of a constant ${ }^{12} \mathrm{C} /{ }^{13} \mathrm{C}$ isotopic ratio to derive the ${ }^{14} \mathrm{~N} /{ }^{15} \mathrm{~N}$ ratio in $\mathrm{C}^{15} \mathrm{~N}$ containing molecules. We take the role of the ortho/para ratio of molecular $\mathrm{H}_{2}$ into account in the $\mathrm{H}_{2} \mathrm{D}^{+}+\mathrm{H}_{2}$ and ${ }^{14} \mathrm{~N}^{+}\left({ }^{15} \mathrm{~N}^{+}\right)+\mathrm{H}_{2}$ chemical reactions in an approximate way: we did not compute the full ortho/para equilibrium as in the models of Flower et al. (2006), Pagani et al. (2011), Faure et al. (2013) and instead introduce it as a model parameter, which can be varied. Faure et al. (2013) have found a value of $10^{-3}$ for temperatures below $15 \mathrm{~K}$.

Apart from exchange reactions, reactions involving isotopic molecules are assumed to have the same total rate constant as those involving the main isotope except for the reaction of ${ }^{15} \mathrm{~N}^{+}$with $\mathrm{H}_{2} / \mathrm{HD} / \mathrm{D}_{2}$. The various reaction channels are obtained from statistical considerations, in the absence of experimental information. We restrict carbon-containing molecules to three carbon atoms, nitrogen-containing molecules to two nitrogen atoms, and consider full deuteration as in our previous studies (Roueff et al. 2005). Within these constraints, the number of species considered in the model is 307 linked through more than 5400 chemical reactions. We consider two different models as displayed in Table 4. Model (a) may be considered as a template of TMC1, and it assumes a density of hydrogen nuclei $n_{H}=2 \times 10^{4} \mathrm{~cm}^{-3}$. The elemental abundance of carbon relative to hydrogen nuclei is taken as $4.15 \times 10^{-5}$ to reproduce the derived relative abundance of CO (Ohishi et al. 1992). We derive the oxygen elemental abundance by imposing a $\mathrm{C} / \mathrm{O}$ ratio of
Table 4. Model definitions.

\begin{tabular}{lll}
\hline \hline & Model (a) & Model (b) \\
\hline Density $n_{\mathrm{H}}\left(\mathrm{cm}^{-3}\right)$ & $2 \times 10^{4}$ & $2 \times 10^{5}$ \\
Temperature $(\mathrm{K})$ & 10 & 10 \\
Cosmic ionization rate per $\mathrm{H}_{2}\left(\mathrm{~s}^{-1}\right)$ & $1.3 \times 10^{-17}$ & $1.3 \times 10^{-17}$ \\
\hline $\mathrm{He} / \mathrm{H}$ & 0.1 & 0.1 \\
$\mathrm{C} / \mathrm{H}$ & $4.15 \times 10^{-5}$ & $1.4 \times 10^{-5}$ \\
$\mathrm{~N} / \mathrm{H}$ & $6.4 \times 10^{-5}$ & $2.1 \times 10^{-5}$ \\
$\mathrm{O} / \mathrm{H}$ & $6 \times 10^{-5}$ & $2.0 \times 10^{-5}$ \\
$\mathrm{~S} / \mathrm{H}$ & $8.0 \times 10^{-8}$ & $8.0 \times 10^{-8}$ \\
$\mathrm{Fe} / \mathrm{H}$ & $1.5 \times 10^{-9}$ & $1.5 \times 10^{-9}$ \\
\hline
\end{tabular}

Notes. The $\mathrm{C} /{ }^{13} \mathrm{C}$ and $\mathrm{N} /{ }^{15} \mathrm{~N}$ ratios are respectively taken as 68 (Milam et al. 2005) and 440 (Marty et al. 2011).

0.7 appropriate for TMC1 and take the nitrogen elemental abundance used by Le Gal et al. (2014) in their work on nitrogen chemistry. The elemental abundance of sulfur is not well constrained, and we have taken the low metal case value of $8.0 \times$ $10^{-8}$. Model (b) is more representative of a prestellar core with a density of $2 \times 10^{5} \mathrm{~cm}^{-3}$ similar to L134N or Barnard 1 (B1) where the elemental abundances of carbon, oxygen, and nitrogen are reduced by a factor of 3 to account for depletion. $T=10 \mathrm{~K}$ in both cases and the cosmic ionization rate $\zeta$ per $\mathrm{H}_{2}$ is $1.3 \times$ $10^{-17} \mathrm{~s}^{-1}$ as in Le Gal et al. (2014).

\subsection{Results}

We summarize our results obtained with a $10^{-3}$ value of the $\mathrm{o} / \mathrm{p}$ ratio of $\mathrm{H}_{2}$ in Table 5 and give some observational values for comparison. Time-dependent effects may be visualized from the values reported at $10^{6}$ years and at steady state for model (a). Steady state is reached after a few $10^{7}$ and $10^{6}$ years for models (a) and (b), respectively. Since there are fewer ${ }^{15} \mathrm{~N}$ enrichment reactions than previously assumed (Terzieva \& Herbst 2000), most nitrogen containing species are found to have isotopic abundance ratios close to the solar value $\left({ }^{14} \mathrm{~N} /{ }^{15} \mathrm{~N}=440\right)$ given by the Genesis mission (Marty et al. 2011).

\section{Discussion}

We display the time dependence of various isotopic ratios and fractional abundances relative to $\mathrm{H}_{2}$ and discuss the chemical behavior involved in the fractionation processes for the two reported models. We first consider in Fig. 1 the reservoirs of nitrogen, atomic, and molecular nitrogen, as well as $\mathrm{N}_{2} \mathrm{H}^{+}$ions that are chemically linked to $\mathrm{N}_{2}$. Atomic nitrogen becomes depleted in ${ }^{15} \mathrm{~N}$ after about $10^{5}$ years, whereas molecular nitrogen is slightly enriched. These evolution times are also required to build significant amounts of molecular compounds, which compare satisfactorily with available observations. The overall dependence of $\mathrm{N}_{2} \mathrm{H}^{+}$follows closely that of $\mathrm{N}_{2}$ as it is formed from the $\mathrm{N}_{2}+\mathrm{H}_{3}{ }^{+}$reaction, with a slight decoupling between ${ }^{15} \mathrm{NNH}^{+}$and $\mathrm{N}^{15} \mathrm{NH}^{+}$at long evolution times. We find that the isotopic ratio of the $\mathrm{N}_{2} \mathrm{H}^{+}$ions displays an almost constant value close to the solar value after some $10^{5}$ years. They are in good agreement with observations in $\mathrm{B} 1$ but disagree by a factor of 2 for L1544. The trend that ${ }^{15} \mathrm{NNH}^{+}$is less abundant than $\mathrm{N}^{15} \mathrm{NH}^{+}$ is reproduced in our results as a result of the differences of endothermicity in their reactions with $\mathrm{N}_{2}$. We checked that introducing ${ }^{15} \mathrm{~N}_{2}$ and species containing two ${ }^{15} \mathrm{~N}$ atoms had no effect on these ratios. We could not find any gas-phase mechanism able 
E. Roueff et al.: Isotopic fractionation of carbon, deuterium, and nitrogen: a full chemical study

Table 5. Model (a) and (b) results and observations. ss means stationary state. The value of the o/p ratio of $\mathrm{H}_{2}$ is taken as $10^{-3}$.

\begin{tabular}{|c|c|c|c|c|c|c|}
\hline & \multicolumn{2}{|c|}{ Model (a) } & \multirow{2}{*}{$\begin{array}{l}\text { Model (b) } \\
\text { ss }\end{array}$} & \multirow[t]{2}{*}{ TMC1 } & \multirow[t]{2}{*}{ L1544 } & \multirow[t]{2}{*}{ B1 } \\
\hline & $t=10^{6} \mathrm{yr}$ & ss & & & & \\
\hline Electronic fraction & $1.4 \times 10^{-8}$ & $2.8 \times 10^{-8}$ & $1.7 \times 10^{-8}$ & & & \\
\hline $\mathrm{N} /{ }^{15} \mathrm{~N}$ & 440 & 456 & 455 & & & \\
\hline $2 \times \mathrm{N}_{2} /{ }^{15} \mathrm{NN}$ & 438 & 431 & 437 & & & \\
\hline $\mathrm{NH} /{ }^{15} \mathrm{NH}$ & 429 & 428 & 421 & & & \\
\hline $\mathrm{NH} / \mathrm{ND}$ & 16 & 31 & 9 & & & \\
\hline $\mathrm{NH}_{3} / \mathrm{H}_{2}$ & $6.7 \times 10^{-9}$ & $1.3 \times 10^{-9}$ & $6.0 \times 10^{-9}$ & $2 \times 10^{-8(8)}$ & & \\
\hline $\mathrm{NH}_{3} /{ }^{15} \mathrm{NH}_{3}$ & 333 & 386 & 387 & & & $300_{-40}^{+55(1)}$ \\
\hline $\mathrm{NH}_{2} \mathrm{D} / \mathrm{H}_{2}$ & $3.8 \times 10^{-10}$ & $5.8 \times 10^{-11}$ & $3.3 \times 10^{-10}$ & $4 \times 10^{-10(9)}$ & & \\
\hline $\mathrm{NH}_{2} \mathrm{D} /{ }^{15} \mathrm{NH}_{2} \mathrm{D}$ & 215 & 276 & 336 & & & $230_{-55}^{+105(1)}$ \\
\hline $\mathrm{NH}_{3} / \mathrm{NH}_{2} \mathrm{D}$ & 18 & 22 & 18 & $50^{(9)}$ & & \\
\hline $\mathrm{N}_{2} \mathrm{H}^{+} / \mathrm{H}_{2}$ & $4.8 \times 10^{-10}$ & $1.3 \times 10^{-10}$ & $2.1 \times 10^{-10}$ & $5 \times 10^{-10(8)}$ & & \\
\hline $\mathrm{N}_{2} \mathrm{H}^{+} / \mathrm{N}^{15} \mathrm{NH}^{+}$ & 431 & 430 & 423 & & $1050^{ \pm 220(2)}$ & $400_{-65}^{+100(1)}$ \\
\hline $\mathrm{N}_{2} \mathrm{H}^{+} /{ }^{15} \mathrm{NNH}^{+}$ & 437 & 432 & 433 & & $1110^{ \pm 240(2)}$ & $>600^{-65}$ \\
\hline $\mathrm{N}_{2} \mathrm{H}^{+} / \mathrm{N}_{2} \mathrm{D}^{+}$ & 16 & 29 & 8.6 & $12.5^{(9)}$ & & $2.9^{(1)}$ \\
\hline $\mathrm{CN} / \mathrm{H}_{2}$ & $6.8 \times 10^{-9}$ & $5.5 \times 10^{-9}$ & $1.2 \times 10^{-9}$ & $3 \times 10^{-8(8)}$ & & \\
\hline $\mathrm{CN} /{ }^{13} \mathrm{CN}$ & 67 & 84 & 63 & & & $50_{-11}^{+19(1)}$ \\
\hline $\mathrm{CN} / \mathrm{C}^{15} \mathrm{~N}$ & 430 & 449 & 445 & & & $240_{-65}^{+1135(1)}$ \\
\hline${ }^{13} \mathrm{CN} / \mathrm{C}^{15} \mathrm{~N}$ & 6.4 & 5.3 & 7.0 & & $7.5^{ \pm 1(3)}$ & \\
\hline $\mathrm{HCN} / \mathrm{H}_{2}$ & $7.4 \times 10^{-9}$ & $5.9 \times 10^{-10}$ & $5.4 \times 10^{-10}$ & $2 \times 10^{-8(8)}$ & & \\
\hline $\mathrm{HCN} / \mathrm{H}^{13} \mathrm{CN}$ & 93 & 168 & 114 & & & $30_{-4}^{+7}(1)$ \\
\hline $\mathrm{HCN} / \mathrm{HC}^{15} \mathrm{~N}$ & 398 & 445 & 453 & & & $165_{-20}^{+30}(1)$ \\
\hline $\mathrm{H}^{13} \mathrm{CN} / \mathrm{HC}^{15} \mathrm{~N}$ & 4.3 & 2.6 & 4.0 & $2-4.5^{(5)}$ & & $5.5 \pm 1^{(1)}$ \\
\hline $\mathrm{HCN} / \mathrm{DCN}$ & 43 & 96 & 22 & & & $20_{-10}^{+6}(1)$ \\
\hline $\mathrm{HNC} / \mathrm{H}_{2}$ & $5.6 \times 10^{-9}$ & $7.4 \times 10^{-10}$ & $8.4 \times 10^{-10}$ & $2 \times 10^{-8(8)}$ & & \\
\hline $\mathrm{HNC} / \mathrm{HN}^{13} \mathrm{C}$ & 93 & 180 & 121 & $54-72^{(4)}$ & & $20_{-4}^{+5}(1)$ \\
\hline $\mathrm{HNC} / \mathrm{H}^{15} \mathrm{NC}$ & 405 & 442 & 446 & $250-330^{(4)}$ & & $75_{-15}^{+45}(1)$ \\
\hline $\mathrm{HN}^{13} \mathrm{C} / \mathrm{H}^{15} \mathrm{NC}$ & 2.5 & 1.75 & 3.7 & $4.6 \pm 0.6^{(4)}$ & & $3.7^{-15} \pm 1^{(1)}$ \\
\hline HNC/DNC & 23 & 66 & 16 & & & $2.9_{-0.19}^{+1.1(1)}$ \\
\hline $\mathrm{NO} / \mathrm{H}_{2}$ & $1 \times 10^{-7}$ & $3.1 \times 10^{-8}$ & $4.1 \times 10^{-8}$ & $2.7 \times 10^{-8(10)}$ & & -0.9 \\
\hline $\mathrm{NO} /{ }^{15} \mathrm{NO}$ & 438 & 451 & 446 & & & \\
\hline $\mathrm{CO} / \mathrm{H}_{2}$ & $8.1 \times 10^{-5}$ & $8.0 \times 10^{-5}$ & $2.8 \times 10^{-5}$ & $8 \times 10^{-5}(8)$ & & \\
\hline $\mathrm{CO} /{ }^{13} \mathrm{CO}$ & 68 & 67.4 & 68 & & & \\
\hline $\mathrm{CH} / \mathrm{H}_{2}$ & $1.3 \times 10^{-9}$ & $1.7 \times 10^{-9}$ & $1.7 \times 10^{-10}$ & $2 \times 10^{-8(8)}$ & & \\
\hline $\mathrm{CH} /{ }^{13} \mathrm{CH}$ & 74 & 154 & 71 & $>71^{(6)}$ & & \\
\hline $\mathrm{HCO}^{+} / \mathrm{H}_{2}$ & $2.5 \times 10^{-9}$ & $3.610^{-10}$ & $5.7 \times 10^{-10}$ & $8 \times 10^{-9(8)}$ & & \\
\hline $\mathrm{HCO}^{+} / \mathrm{H}^{13} \mathrm{CO}^{+}$ & 56 & 65 & 56 & & & $59^{(7)}$ \\
\hline $\mathrm{HCO}^{+} / \mathrm{DCO}^{+}$ & 15 & 29 & 8.4 & $50^{(9)}$ & & \\
\hline
\end{tabular}

References. (1) Daniel et al. (2014); (2) Bizzocchi et al. (2013); (3) Hily-Blant et al. (2013b); (4) Liszt \& Ziurys (2012); (5) Hily-Blant et al. (2013a); (6) Sakai et al. (2013); (7) Hirano \& Liu (2014) assuming CO/C ${ }^{18} \mathrm{O}=500$; (8) Ohishi et al. (1992); (9) Tiné et al. (2000); (10) Gerin et al. (1993).

to generate such a high ratio in prestellar core conditions. The high isotopic ratio found in L1544 implies an equivalently high ratio for molecular nitrogen, which strongly contradicts our findings. These results are markedly different from those derived by Hily-Blant et al. (2013b), who find a moderate ${ }^{15} \mathrm{~N}$ enrichment, because these authors introduced the ${ }^{15} \mathrm{~N}+\mathrm{N}_{2} \mathrm{H}^{+}$fractionation reaction, which does not occur ${ }^{1}$.

\subsection{Nitrogen hydrides}

We display in Fig. 2 the time evolution of the isotopic ratios of nitrogen hydrides and of their fractional abundances relative to $\mathrm{H}_{2} . \mathrm{NH}_{3}$ and $\mathrm{NH}_{2}$ show very similar behavior in that they both result from the reaction chain starting with the ${ }^{14} \mathrm{~N}^{+}+\mathrm{H}_{2}$ reactions. The species $\mathrm{NH}_{2}$ and $\mathrm{NH}_{3}$ are found to be enriched in ${ }^{15} \mathrm{~N}$ owing to the ${ }^{15} \mathrm{~N}^{+}+\mathrm{o}-\mathrm{H}_{2}$ reaction, which has a slightly weaker

\footnotetext{
1 These authors also interchanged the endothermicities of the ${ }^{15} \mathrm{NNH}^{+}$ and $\mathrm{N}^{15} \mathrm{NH}^{+}$reactions with $\mathrm{N}$ and $\mathrm{N}_{2}$.
}

endothermicity, as reported in Table 2, than the corresponding ${ }^{14} \mathrm{~N}^{+}+\mathrm{o}-\mathrm{H}_{2}$ reaction, a difference which slightly favors ${ }^{15} \mathrm{NH}^{+}$ formation. Nevertheless, despite the large uncertainties regarding the rate of the $\mathrm{N}^{+}+\mathrm{H}_{2}$ reaction, our results are in fair agreement with the results of Daniel et al. (2014) for prestellar core B1. Since the $\mathrm{N}^{+}+\mathrm{HD} \rightarrow \mathrm{ND}^{+}+\mathrm{H}$ reaction has weaker endothermicity than the $\mathrm{N}^{+}+\mathrm{H}_{2} \rightarrow \mathrm{NH}^{+}+\mathrm{H}$ reaction, the modeled ${ }^{14} \mathrm{NH}_{2} \mathrm{D} /{ }^{15} \mathrm{NH}_{2} \mathrm{D}$ ratio behaves somewhat differently than the ${ }^{14} \mathrm{NH}_{3} /{ }^{15} \mathrm{NH}_{3}$ ratio. The ratio exhibits large variations around $10^{5}$ years and decreases below that of $\mathrm{NH}_{3}$ at long times and at steady state.

The observed values are compatible with calculations at sufficiently long times. The values of this ratio reported in Gerin et al. (2009) have been found to be too high as a result of assuming a single excitation rotational temperature. The future availability of collisional excitation rates of $\mathrm{NH}_{2} \mathrm{D}$ by $\mathrm{H}_{2}$ (Daniel et al. 2014) may give rise to additional changes. NH does not follow the same trend as $\mathrm{NH}_{2}$ and $\mathrm{NH}_{3}$ and is only slightly enriched in ${ }^{15} \mathrm{~N}$. As discussed by Hily-Blant et al. (2013b), $\mathrm{NH}$ is mainly 

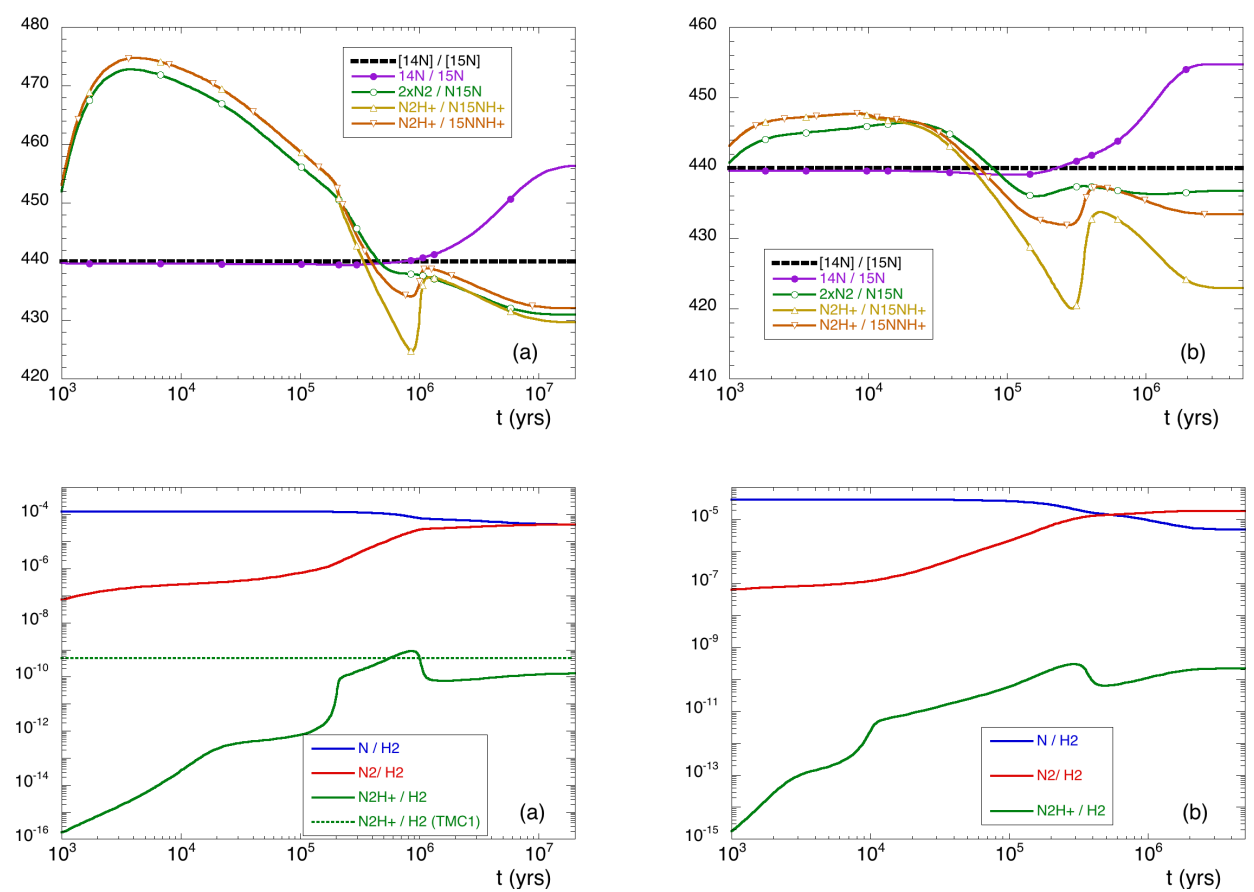

Fig. 1. Upper panel: time dependence of $\mathrm{N} /{ }^{15} \mathrm{~N}$ isotopic ratios in atomic and molecular nitrogen and $\mathrm{N}_{2} \mathrm{H}^{+}$ions. a) and b) correspond to the models defined in Table 4; the black heavy dotted line represents the elemental $\mathrm{N} /{ }^{15} \mathrm{~N}$. Lower panel: time dependence of the fractional abundances relative to $\mathrm{H}_{2}$ of $\mathrm{N}, \mathrm{N}_{2}$, and $\mathrm{N}_{2} \mathrm{H}^{+}$for models (a) and (b). The value reported for $\mathrm{N}_{2} \mathrm{H}^{+}$towards TMC1 (Ohishi et al. 1992) is displayed as a horizontal green dashed line.
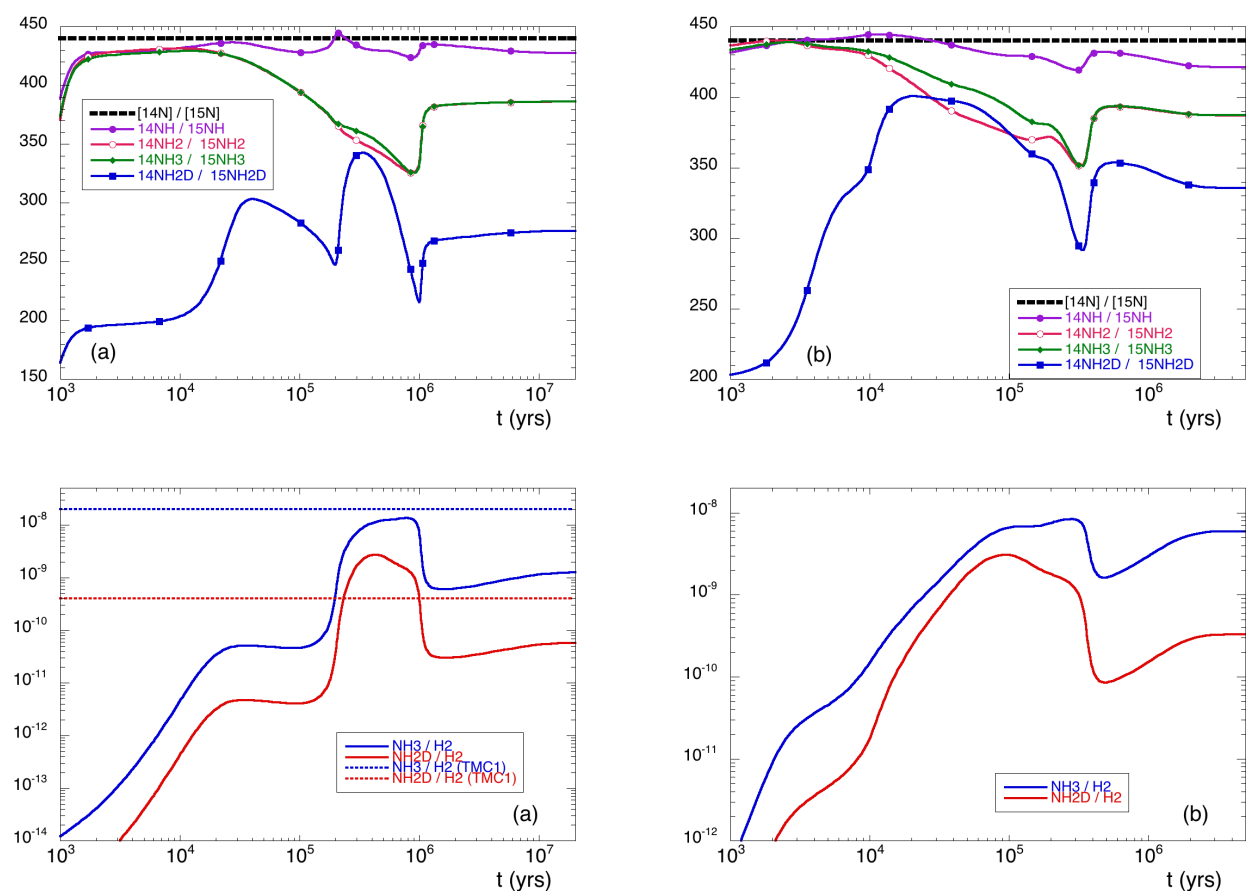

Fig. 2. Upper panel: time dependence of $\mathrm{N} /{ }^{15} \mathrm{~N}$ isotopic ratios in nitrogen hydrides. a) and b) correspond to the models defined in Table 4; The black heavy dotted line represents the elemental $\mathrm{N} /{ }^{15} \mathrm{~N}$. Lower panel: time dependence of the fractional abundances relative to $\mathrm{H}_{2}$ of $\mathrm{NH}, \mathrm{NH}_{2}, \mathrm{NH}_{3}$, and $\mathrm{NH}_{2} \mathrm{D}$ for models (a) and (b). The values reported for $\mathrm{NH}_{3}$ (Ohishi et al. 1992) and $\mathrm{NH}_{2} \mathrm{D}$ (Tiné et al. 2000) towards TMC1 are displayed as horizontal blue and red dashed lines, respectively, in the left panel.

formed from the dissociative recombination (DR) of $\mathrm{N}_{2} \mathrm{H}^{+}$, a reaction that has been recently revisited by Vigren et al. (2012), who derive a branching ratio towards a $\mathrm{NH}$ of $7 \%$. We checked that this analysis still holds for model (b) even if the reaction of $\mathrm{N}_{2} \mathrm{H}^{+}$with $\mathrm{CO}$ becomes more efficient. The formation route of $\mathrm{NH}$ through $\mathrm{NH}_{2}^{+}$recombination may take over for highly depleted $\mathrm{CO}$.

\subsection{Nitriles and isonitriles}

Deriving ${ }^{15} \mathrm{~N}$ isotopic ratios of $\mathrm{CN}, \mathrm{HCN}$, and $\mathrm{HNC}$ from observations is a difficult challenge because the transitions of the main isotopologues are optically thick. Then, most of the reported observational values of the ${ }^{14} \mathrm{~N} /{ }^{15} \mathrm{~N}$ molecular ratios are obtained from the ratios of the minor isotopologues ${ }^{13} \mathrm{CN} / \mathrm{C}^{15} \mathrm{~N}$, $\mathrm{H}^{13} \mathrm{CN} / \mathrm{HC}^{15} \mathrm{~N}$, and $\mathrm{HN}^{13} \mathrm{C} / \mathrm{H}^{15} \mathrm{NC}$, which is subsequently multiplied by an assumed $\mathrm{C} /{ }^{13} \mathrm{C}$ value, usually taken as 68 (Milam et al. 2005).

\subsection{1. ${ }^{13} \mathrm{C} /{ }^{15} \mathrm{~N}$ ratios}

We test these hypotheses in our models by explicitly introducing fractionation reactions of ${ }^{13} \mathrm{C}$, as discussed in Sect. 2. Table 5 shows that the ${ }^{13} \mathrm{C}$ isotopic ratios of $\mathrm{CN}, \mathrm{HCN}$, and $\mathrm{HNC}$ vary both with time and density. Figure 3 displays the ${ }^{13} \mathrm{CN} / \mathrm{C}^{15} \mathrm{~N}$, $\mathrm{H}^{13} \mathrm{CN} / \mathrm{HC}^{15} \mathrm{~N}$, and $\mathrm{HN}^{13} \mathrm{C} / \mathrm{H}^{15} \mathrm{NC}$ ratios as a function of time for the two considered models. The deviation from the elemental ratio of 6.48 is significant for $\mathrm{HCN}, \mathrm{HNC}$, and $\mathrm{CN}$. 

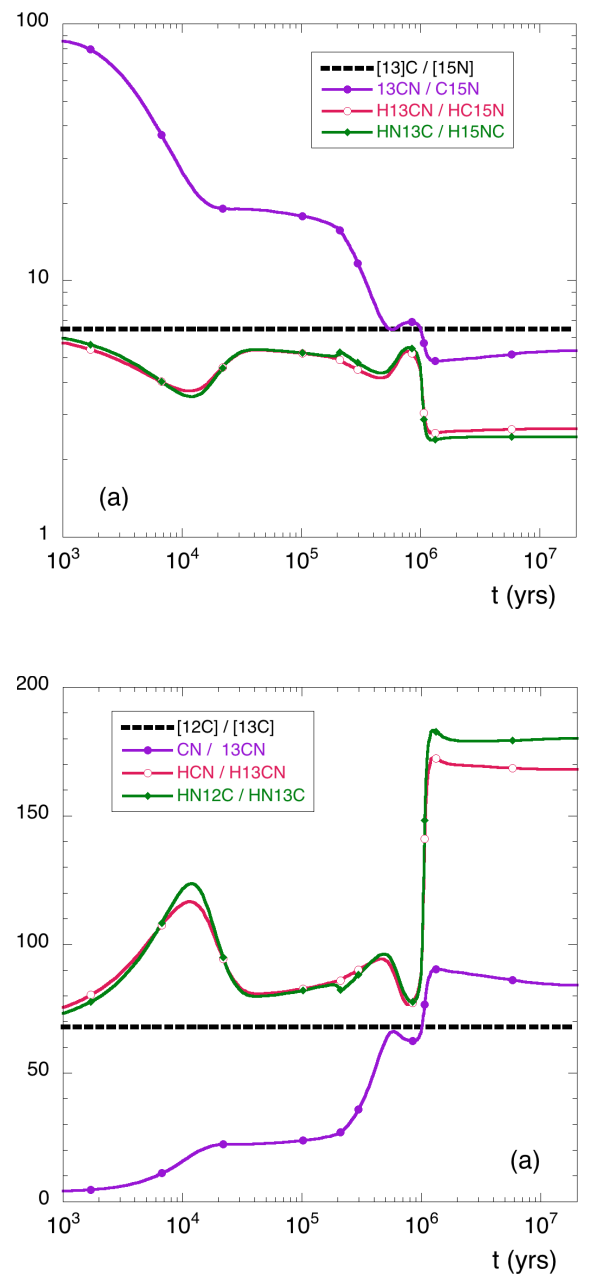
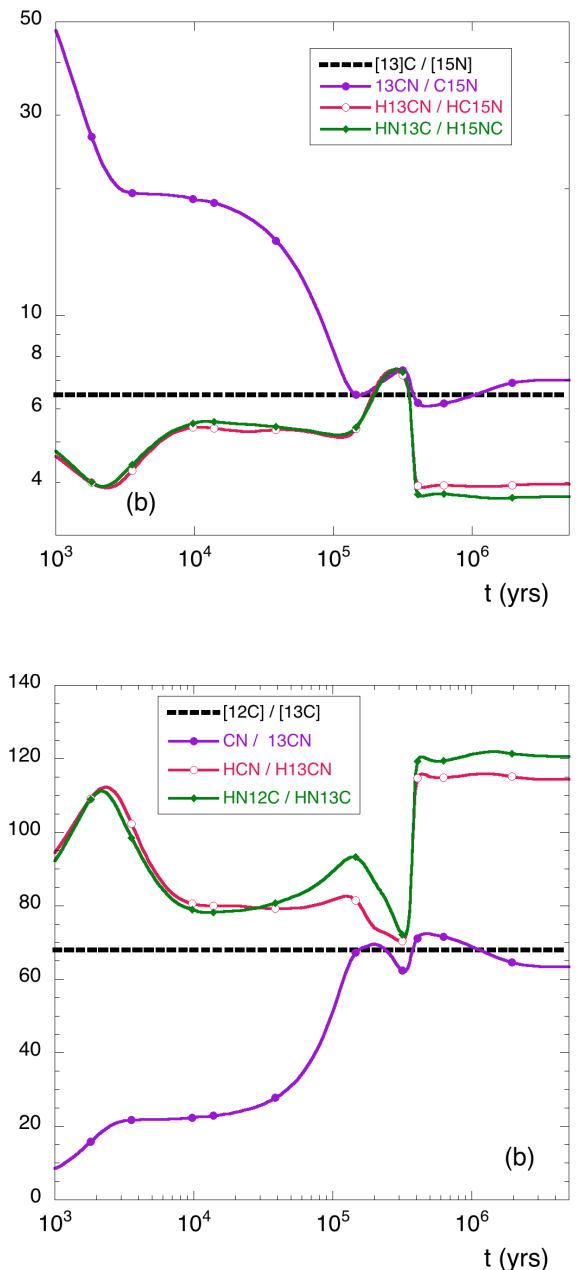

Fig. 3. Time evolution of ${ }^{13} \mathrm{C} /{ }^{15} \mathrm{~N}$ ratios in $\mathrm{CN}, \mathrm{HCN}$, and HNC for models (a) and (b). The ${ }^{13} \mathrm{C} /{ }^{15} \mathrm{~N}$ elemental ratio is displayed as a heavy dotted line.
Fig. 4. Time dependence of $\mathrm{C} /{ }^{13} \mathrm{C}$ isotopic ratios in $\mathrm{CN}$, $\mathrm{HCN}$, and $\mathrm{HNC}$. a) and b) correspond to the models defined in Table 4.

\subsection{2. ${ }^{13} \mathrm{C}$ chemistry}

We now consider the time dependences of the ${ }^{12} \mathrm{C} /{ }^{13} \mathrm{C}$ isotopic ratios in $\mathrm{CN}, \mathrm{HCN}$, and $\mathrm{HNC}$ species as displayed in Fig. 4. The time-dependent ratio displays large variations, because there are various reactions incorporating ${ }^{13} \mathrm{C}$ in the molecules. The elemental value of the ratio (68) is fulfilled in a narrow range around $1 \mathrm{Myr}$ for model (a) and $2 \times 10^{5}$ y for model (b), but steady state values are significantly different except for $\mathrm{CN}$. This relatively complex behavior results from the many different reaction channels involved in ${ }^{13} \mathrm{C}$ chemistry. We then also consider other ${ }^{13} \mathrm{C}$ containing species and display the ${ }^{12} \mathrm{C} /{ }^{13} \mathrm{C}$ ratio in $\mathrm{C}, \mathrm{CH}, \mathrm{CO}$, and $\mathrm{HCO}^{+}$in Fig. 5, as well as their fractional abundances relative to $\mathrm{H}_{2}$. The ${ }^{12} \mathrm{C} /{ }^{13} \mathrm{C}$ isotopic ratios of the various molecules are highly dependent on the evolution time. The transition from gas-phase atomic carbon towards $\mathrm{CO}$ controls the ${ }^{13} \mathrm{C}$ enrichment. As long as there is still a relatively high carbon-atom concentration in the gas phase, there is enough free ${ }^{13} \mathrm{C}$ to allow strong enrichment of $\mathrm{CN}$ through the ${ }^{13} \mathrm{C}+\mathrm{CN}$ reaction. When $\mathrm{CO}$ molecules become the reservoir of carbon, even if in that case the ${ }^{13} \mathrm{C}$ concentration is low, the ${ }^{13} \mathrm{C}^{+}+{ }^{12} \mathrm{CO} \rightarrow{ }^{12} \mathrm{C}^{+}+$ ${ }^{13} \mathrm{CO}$ reaction still leads to a small ${ }^{13} \mathrm{CO}$ enrichment (Langer \& Penzias 1990; Milam et al. 2005). Although this small excess is not measurable in $\mathrm{CO}$, significant amounts of ${ }^{13} \mathrm{C}$ are locked up in $\mathrm{CO}$, and most of the other carbon containing species become depleted in ${ }^{13} \mathrm{C}$, as found for $\mathrm{CH}$ and other carbon chains. This effect is seen in Fig. 5 for the isotopic ratio of $\mathrm{CH}$ in model (a) at steady state where $\mathrm{CO}$ is slightly enriched, leading to a significant depletion of ${ }^{13} \mathrm{C}$ in $\mathrm{CH}$. Our results for $\mathrm{C}$ and $\mathrm{HCO}^{+}$are similar to those of Furuya et al. (2011), who studied the ${ }^{13} \mathrm{C}$ fractionation of multiple carbon chains by explicitly introducing the dependence of the ${ }^{13} \mathrm{C}$ position in the chain. We see that $\mathrm{HCO}^{+}$ is marginally enriched in ${ }^{13} \mathrm{C}$ at steady state, whereas $\mathrm{HCN}$ and $\mathrm{HNC}$ are significantly depleted in ${ }^{13} \mathrm{C}$. We also note that $\mathrm{CN}$ and $\mathrm{HCO}^{+}$may react via proton transfer to give $\mathrm{CO}+\mathrm{HNC}^{+}$, and have checked, at the DFT level, the absence of any barrier. The corresponding reaction rate is $2.2 \times 10^{-9}\left(\frac{T}{300}\right)^{-0.4} \mathrm{~cm}^{3} \mathrm{~s}^{-1}$ when using the capture rate theory. This reaction has not been included in any chemical database up to now.

HNC has recently been shown to react with atomic carbon (Loison et al. 2014), which leads to the different steady state isotopic ratios obtained for $\mathrm{HCN}$ and $\mathrm{HNC}$. The $\mathrm{CN}$ chemistry is then somewhat decoupled from that of HCN and HNC. HCN and $\mathrm{HNC}$ are formed at relatively long times via $\mathrm{CN}+\mathrm{H}_{3}{ }^{+} \rightarrow$ $\mathrm{HNC}^{+} / \mathrm{HCN}^{+}+\mathrm{H}_{2}$, followed immediately by $\mathrm{HNC}^{+}+\mathrm{H}_{2} \rightarrow$ $\mathrm{HCNH}^{+}+\mathrm{H}$, giving back $\mathrm{HCN}$ and $\mathrm{HNC}$ via DR (Mendes et al. 2012). With the adopted elemental abundances, the main $\mathrm{CN}$ destruction reactions are, however, $\mathrm{O}+\mathrm{CN}$ and $\mathrm{N}+\mathrm{CN}$ so that the $\mathrm{HCNH}^{+} / \mathrm{HCN}^{+} / \mathrm{HNC}^{+} / \mathrm{HCN} / \mathrm{HNC} / \mathrm{CN}$ network is not a closed system in contrast to models including coupled gas-grain chemistry (Loison et al. 2014).

\subsection{3. ${ }^{15} \mathrm{~N}$ fractionation}

We now display the $\mathrm{N} /{ }^{15} \mathrm{~N}$ fractionation in nitriles, as well as that of NO in Fig. 6. The time dependences of the isotopic ratios are markedly different in the two models, except for NO. Whereas 

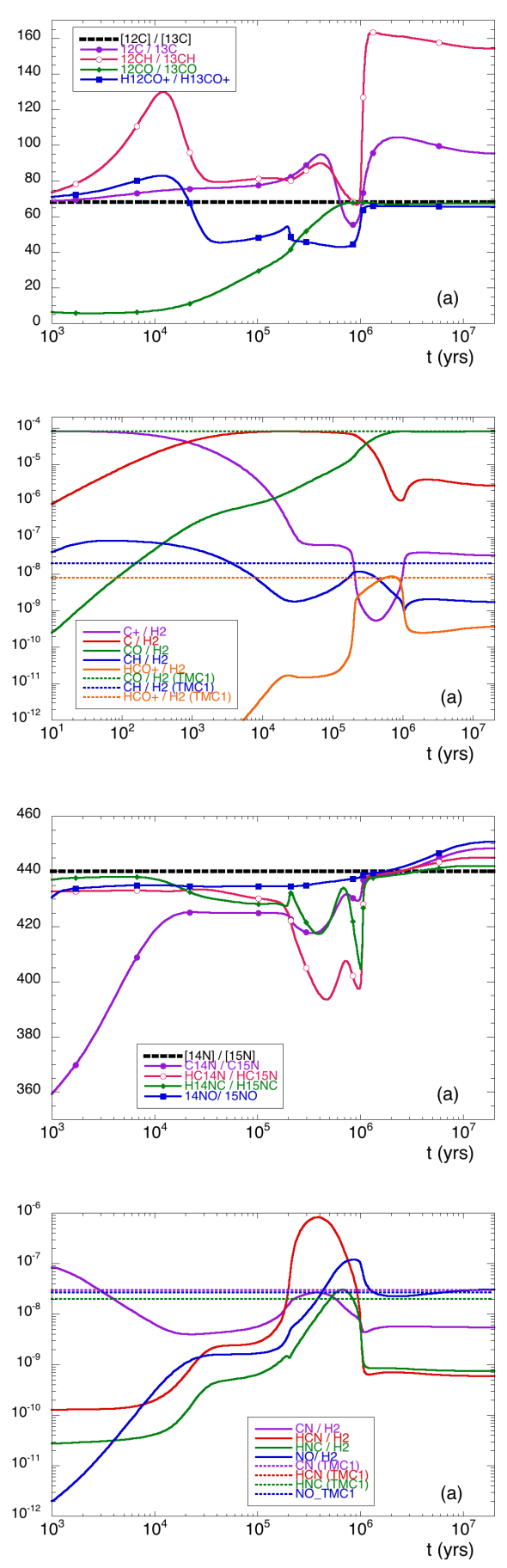
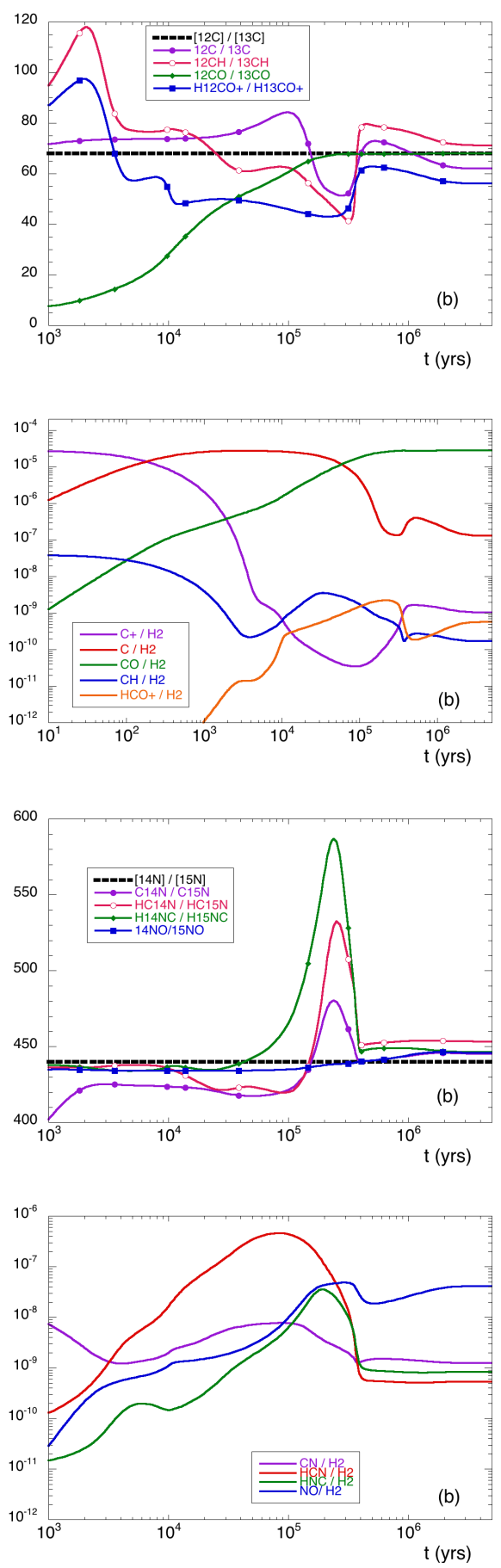

Fig. 5. Upper panel: time dependence of $\mathrm{C} /{ }^{13} \mathrm{C}$ isotopic ratios in $\mathrm{C}, \mathrm{CH}, \mathrm{CO}$, and $\mathrm{HCO}^{+}$. The black heavy dotted line represents the elemental ${ }^{12} \mathrm{C} /{ }^{13} \mathrm{C}$. Lower panel: time dependence of the fractional abundances relative to $\mathrm{H}_{2}$ of $\mathrm{C}^{12} \mathrm{C}^{+}, \mathrm{CO}, \mathrm{CH}$, and $\mathrm{HCO}^{+}$, for models (a) and (b). The observational values towards TMC1 (Ohishi et al. 1992) are displayed as horizontal dashed lines with corresponding colors in the left panel. a) and b) correspond to the models defined in Table 4.

Fig. 6. Time dependence of $\mathrm{N} /{ }^{15} \mathrm{~N}$ isotopic ratios in $\mathrm{CN}, \mathrm{HCN}, \mathrm{HNC}$, and $\mathrm{NO}$. a) and b) correspond to the models defined in Table 4.
$\mathrm{CN}, \mathrm{HCN}$, and $\mathrm{HNC}$ are somewhat enriched in ${ }^{15} \mathrm{~N}$ for model (a) both at intermediates times and steady state, the opposite result is obtained in model (b) after $10^{5}$ years. We also display the time dependences of the fractional abundances of these molecules in Fig. 7 in order to better understand the previously described differences observed in the various fractionation ratios.

Our model (a) is intended to be representative of TMC1, a moderately dense cloud in an early evolutionary stage. We see that the various abundances and ratios are very sensitive to the chosen "age", which is assumed to be the relevant chemical evolution time. Considering a TMC1 age of 1 Myr leads to reasonable agreement with the sparse observations available, see Table 5. Model (b) is more likely to be representative of a denser evolved molecular cloud, such as L134N, L1544, and Barnard B1, where elemental C, O, and $\mathrm{N}$ are partially depleted through sticking on grains. Steady state values obtained with significant depletion conditions (Roueff et al. 2005) may be used as corresponding proxies. We see that ammonia isotopologues are satisfactorily accounted for in our model. The agreement between observed and calculated ${ }^{13} \mathrm{C} /{ }^{15} \mathrm{~N}$ ratios is somewhat misleading since the modeled value mainly results from a significant depletion in the ${ }^{13} \mathrm{C}$ species. The ratios involving $\mathrm{N} /{ }^{15} \mathrm{~N}$ are found close to the elemental value in our model (b) at steady state (although $\mathrm{NH}_{2}$ and $\mathrm{NH}_{3}$ are somewhat enriched in ${ }^{15} \mathrm{~N}$ through the ${ }^{15} \mathrm{~N}^{+}+\mathrm{H}_{2}$ reaction as explained in Sect. 4.1), which agrees with the fact that no significant gas phase fractionation mechanisms have been found. The occurrence of low ratios in B1 observations (Daniel et al. 2014), if real, implies other mechanisms at work. An obvious suggestion lies in the processes involved in adsorption on grains and possible surface reactions. 
E. Roueff et al.: Isotopic fractionation of carbon, deuterium, and nitrogen: a full chemical study


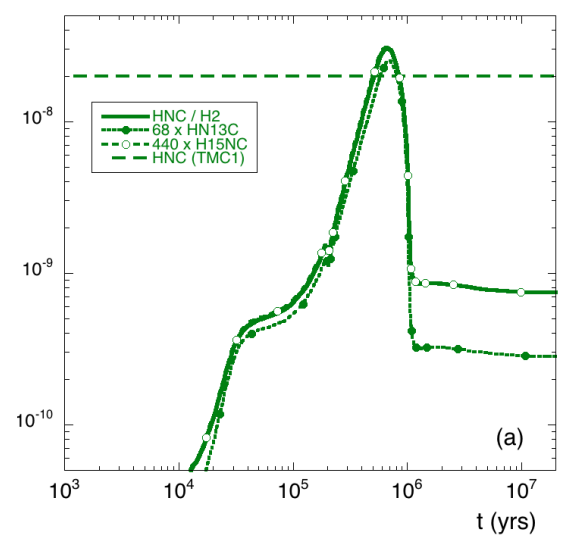

\subsection{Role of the $\mathrm{H}_{2}$ ortho-to-para ratio}

We now test the role of the value of the ortho/para ratio of molecular hydrogen (OPR) in the context of ammonia chemistry and fractionation determination. We ran two additional models in the frame of models (a) and (b) by changing the OPR by a factor of 10 both upward and downward. The abundances of $\mathrm{p}-\mathrm{H}_{2}$ and $\mathrm{o}-\mathrm{H}_{2}$ are expressed as $n\left(\mathrm{p}-\mathrm{H}_{2}\right)=\frac{1}{1+\mathrm{OPR}} n\left(\mathrm{H}_{2}\right)$ and $n\left(\mathrm{o}-\mathrm{H}_{2}\right)=\frac{\mathrm{OPR}}{1+\mathrm{OPR}} n\left(\mathrm{H}_{2}\right)$, respectively. In addition to the reaction of $\mathrm{H}_{2}$ with ${ }^{14} \mathrm{~N}^{+}\left({ }^{15} \mathrm{~N}^{+}\right)$, this ratio is introduced into the reverse reaction of the fractionation of $\mathrm{H}_{3}{ }^{+}$, namely the $\mathrm{H}_{2} \mathrm{D}^{+}+$ $\mathrm{H}_{2}$ reaction that plays a significant role in the deuterium fractionation of various molecules (Pagani et al. 2011) as shown below:

$\begin{array}{llll}\mathrm{H}_{2} \mathrm{D}^{+}+\mathrm{p}-\mathrm{H}_{2} & \rightarrow \mathrm{H}_{3}^{+}+\mathrm{HD}, & k_{1}\left(\mathrm{~cm}^{3} \mathrm{~s}^{-1}\right) \\ \mathrm{H}_{2} \mathrm{D}^{+}+\mathrm{O}-\mathrm{H}_{2} & \rightarrow \mathrm{H}_{3}{ }^{+}+\mathrm{HD}, & k_{2}\left(\mathrm{~cm}^{3} \mathrm{~s}^{-1}\right)\end{array}$

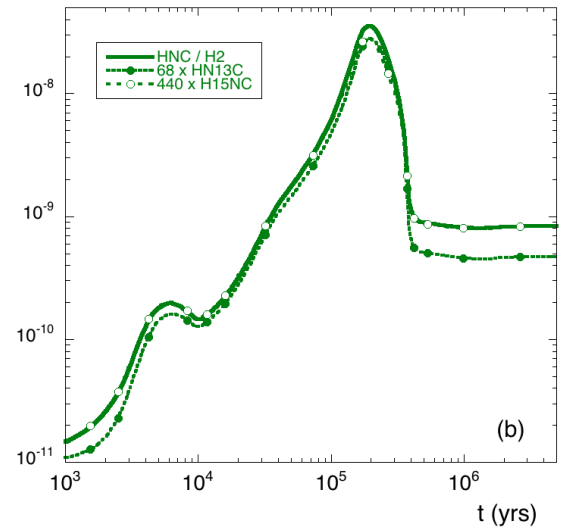

Fig. 7. Time dependence of $\mathrm{CN}, \mathrm{HCN}, \mathrm{HNC}$, and their isotopologues. a) and b) correspond to the models defined in Table 4.

with $k_{1}=2.0 \times 10^{-9} \times \exp (-232 / T)$ and $k_{2}=2.0 \times 10^{-9} \times$ $\exp (-61.5 / T)$.

Tables 6 and 7 display the fractionation values for the three different assumed values of the OPR for models (a) and (b), and Figs. 8 and 9 display the corresponding time evolutions. We see that the curves are almost superposable for times less than $1 \mathrm{Myr}$ for model (a) and less than several $10^{5} \mathrm{y}$ for model (b). The variations are significant at steady state. We find that the competition between the destruction channels of ${ }^{14} \mathrm{~N}^{+}$through its reactions with o- $\mathrm{H}_{2}$ and $\mathrm{CO}$ plays a major role. If $\mathrm{o}-\mathrm{H}_{2}$ is the most efficient destruction channel, which typically occurs for OPR $>200 \times x_{\mathrm{CO}}$ at $10 \mathrm{~K}$, where $x_{\mathrm{CO}}$ is the fractional abundance of $\mathrm{CO}$ relative to $\mathrm{H}_{2}$, formation of $\mathrm{NH}_{4}^{+}$proceeds efficiently. In the opposite case, ${ }^{14} \mathrm{~N}^{+}$is mainly destroyed through reaction with $\mathrm{CO}$ to yield $\mathrm{CO}^{+}$, leading rapidly to $\mathrm{HCO}^{+}$and $\mathrm{NO}^{+}$(which does not react with $\mathrm{H}_{2}$ ). Since the DR rate coefficients of polyatomic ions increase significantly for larger polyatomic ions (the $\mathrm{NH}_{4}^{+}+\mathrm{e}^{-}$ 
Table 6. Dependence of the fractionation ratios on the o/p ratio of $\mathrm{H}_{2}$ for model (a), where ss means stationary state.

\begin{tabular}{lcccccc}
\hline \hline & \multicolumn{2}{c}{ OPR $=10^{-4}$} & \multicolumn{2}{c}{ OPR $=10^{-3}$} & \multicolumn{2}{c}{ OPR $=10^{-2}$} \\
& $t=10^{6} \mathrm{yr}$ & ss & $t=10^{6} \mathrm{yr}$ & ss & $t=10^{6} \mathrm{yr}$ & ss \\
\hline Electronic fraction & $5.1 \times 10^{-8}$ & $2.2 \times 10^{-7}$ & $4.8 \times 10^{-8}$ & $2.1 \times 10^{-7}$ & $3.7 \times 10^{-8}$ & $4.2 \times 10^{-8}$ \\
$\mathrm{~N} /{ }^{15} \mathrm{~N}$ & 440 & 456 & 440 & 456 & 440 & 452 \\
$2 \times \mathrm{N}_{2} /{ }^{15} \mathrm{NN}$ & 438 & 430 & 438 & 431 & 438 & 437 \\
$\mathrm{NH} /{ }^{15} \mathrm{NH}$ & 431 & 429 & 429 & 428 & 426 & 418 \\
$\mathrm{NH} / \mathrm{ND}$ & 16 & 31 & 16 & 31 & 18 & 23 \\
$\mathrm{NH}_{3} /{ }^{15} \mathrm{NH}_{3}$ & 345 & 409 & 333 & 386 & 374 & 395 \\
$\mathrm{NH}_{2} \mathrm{D} /{ }^{15} \mathrm{NH}_{2} \mathrm{D}$ & 206 & 267 & 215 & 276 & 265 & 303 \\
$\mathrm{NH}_{3} / \mathrm{NH}_{2} \mathrm{D}$ & 8 & 14 & 17 & 22 & 43 & 63 \\
$\mathrm{~N}_{2} \mathrm{H}^{+} / \mathrm{N}^{15} \mathrm{NH}^{+}$ & 431 & 429 & 431 & 430 & 429 & 421 \\
$\mathrm{~N}_{2} \mathrm{H}^{+} /{ }^{15} \mathrm{NNH}^{+}$ & 437 & 432 & 437 & 432 & 436 & 433 \\
$\mathrm{~N}_{2} \mathrm{H}^{+} / \mathrm{N}_{2} \mathrm{D}^{+}$ & 16 & 30 & 16 & 29 & 17 & 21 \\
$\mathrm{CN} /{ }^{13} \mathrm{CN}^{15}$ & 67 & 85 & 67 & 84 & 67 & 70 \\
$\mathrm{CN} / \mathrm{C}^{15} \mathrm{~N}$ & 432 & 449 & 430 & 449 & 429 & 434 \\
$\mathrm{HCN} / \mathrm{H}^{13} \mathrm{CN}$ & 92 & 168 & 93 & 168 & 93 & 165 \\
$\mathrm{HCN} / \mathrm{HC}^{15} \mathrm{~N}$ & 401 & 453 & 398 & 445 & 400 & 413 \\
$\mathrm{HCN} / \mathrm{DCN}$ & 44 & 95 & 43 & 96 & 40 & 55 \\
$\mathrm{HNC} / \mathrm{HN}^{13} \mathrm{C}$ & 91 & 178 & 93 & 180 & 97 & 195 \\
$\mathrm{HNC} / \mathrm{H}^{15} \mathrm{NC}$ & 410 & 451 & 405 & 442 & 405 & 410 \\
$\mathrm{HNC} / \mathrm{DNC}$ & 23 & 66 & 23 & 66 & 22 & 32 \\
$\mathrm{HCO} / \mathrm{H}^{13} \mathrm{CO}$ & 57 & 66 & 56 & 65 & 54 & 55 \\
$\mathrm{HCO} / \mathrm{DCO}^{+}$ & 15 & 30 & 15 & 29 & 16 & 19 \\
\hline
\end{tabular}

Table 7. Dependence of the fractionation ratios on the o/p ratio of $\mathrm{H}_{2}$ for model (b) at steady state.

\begin{tabular}{lccc}
\hline \hline & OPR $=10^{-4}$ & OPR $=10^{-3}$ & OPR $=10^{-2}$ \\
\hline Electronic fraction & $2.2 \times 10^{-8}$ & $1.7 \times 10^{-8}$ & $1.1 \times 10^{-8}$ \\
$\mathrm{~N} /{ }^{15} \mathrm{~N}$ & 457 & 455 & 445 \\
$2 \times \mathrm{N}_{2} /{ }^{15} \mathrm{NN}$ & 436 & 437 & 438 \\
$\mathrm{NH} /{ }^{15} \mathrm{NH}$ & 425 & 421 & 418 \\
$\mathrm{NH} / \mathrm{ND}$ & 9 & 9 & 11 \\
$\mathrm{NH}_{3} /{ }^{15} \mathrm{NH}_{3}$ & 396 & 387 & 416 \\
$\mathrm{NH}_{2} \mathrm{D} /{ }^{15} \mathrm{NH}_{2} \mathrm{D}$ & 322 & 336 & 376 \\
$\mathrm{NH}_{3} / \mathrm{NH}_{2} \mathrm{D}$ & 11 & 18 & 33 \\
$\mathrm{~N}_{2} \mathrm{H}^{+} / \mathrm{N}^{15} \mathrm{NH}^{+}$ & 425 & 423 & 417 \\
$\mathrm{~N}_{2} \mathrm{H}^{+} /{ }^{15} \mathrm{NNH}^{+}$ & 434 & 433 & 433 \\
$\mathrm{~N}_{2} \mathrm{H}^{+} / \mathrm{N}_{2} \mathrm{D}^{+}$ & 8.7 & 8.6 & 9.7 \\
$\mathrm{CN} /{ }^{13} \mathrm{CN}$ & 65 & 63 & 60 \\
$\mathrm{CN} / \mathrm{C}^{15} \mathrm{~N}$ & 449 & 445 & 438 \\
$\mathrm{HCN} / \mathrm{H}^{13} \mathrm{CN}$ & 115 & 114 & 107 \\
$\mathrm{HCN} / \mathrm{HC}^{15} \mathrm{~N}$ & 467 & 453 & 458 \\
$\mathrm{HCN} / \mathrm{DCN}$ & 25 & 22 & 18 \\
$\mathrm{HNC} / \mathrm{HN}^{13} \mathrm{C}$ & 120 & 121 & 118 \\
$\mathrm{HNC} / \mathrm{H}^{15} \mathrm{NC}$ & 461 & 446 & 453 \\
$\mathrm{HNC} / \mathrm{DNC}$ & 19 & 16 & 12 \\
$\mathrm{HCO} / \mathrm{H}^{13} \mathrm{CO}{ }^{+}$ & 58 & 56 & 51 \\
$\mathrm{HCO} / \mathrm{DCO}^{+}$ & 8.6 & 8.4 & 9.4 \\
\hline
\end{tabular}

reaction is three times more rapid than $\mathrm{HCO}^{+}+\mathrm{e}^{-}$and twenty times more rapid than $\mathrm{H}_{3}{ }^{+}+\mathrm{e}^{-}$), these two different channels affect the electron abundances and then many other species.

Moreover, the reaction between $\mathrm{NH}_{3}$ and $\mathrm{H}_{3}{ }^{+}$leads to $\mathrm{NH}_{4}^{+}+\mathrm{H}_{2} \cdot \mathrm{NH}_{4}^{+}$then reacts mainly with electrons, returning back to $\mathrm{NH}_{3}$, which subsequently converts to $\mathrm{NH}_{4}^{+}$, amplifying the electron loss through DR. These effects occur when $\mathrm{CO}$ becomes the main carbon reservoir, for sufficiently long evolution times. As a result, the electron fraction is found to decrease when the OPR increases at long evolution times and at steady state.
The decreasing electron abundance with increasing OPR values acts to diminish the effect of all DR reactions and, as a result, to increase the abundances of $\mathrm{H}_{3}{ }^{+}$and $\mathrm{H}_{2} \mathrm{D}^{+}$since $\mathrm{DR}$ is the main destruction channel in our conditions. The abundance of $\mathrm{H}_{2} \mathrm{D}^{+}$is even more enhanced through the $\mathrm{H}_{3}{ }^{+}+\mathrm{HD}$ reaction. Then the abundances of other deuterated molecular ions produced through deuteron transfer reactions of abundant neutrals with $\mathrm{H}_{2} \mathrm{D}^{+}$are increased as well, which affects the subsequent formation of neutral deuterated compounds produced in the DR reactions. Eventually, the HCN/DCN and HNC/DNC ratios are shown to decrease for increasing OPR values. This example demonstrates the complexity of the interplay between the different chemistries.

\section{Conclusions}

We have for the first time built an isotopically substituted gas phase chemical network that includes $\mathrm{D},{ }^{13} \mathrm{C}$, and ${ }^{15} \mathrm{~N}$ species and included it in a time-dependent chemical model. Our model is based on a careful analysis of the possible gas phase mechanisms involved in carbon and nitrogen fractionation by scrutinizing the few available experimental studies and performing DFT and $\mathrm{ab}$ initio quantum calculations on hypothetical reactions to check for the possible presence of barriers in the reaction channels. One important result is that the fractionation reaction of ${ }^{15} \mathrm{~N}$ with $\mathrm{N}_{2} \mathrm{H}^{+}$is unlikely, due to the presence of a barrier, in contrast to the previous hypothesis made by Terzieva \& Herbst (2000). As a result, the modeled isotopic ratios involved in the isotopologues of $\mathrm{N}_{2} \mathrm{H}^{+}$are found to be very close to the elemental values and are similar to each other, in contradiction with observations toward L1544 (Bizzocchi et al. 2013).

The availability of new collisional rate coefficients for the $\mathrm{N}_{2} \mathrm{H}^{+}-\mathrm{H}_{2}$ system (Lique et al. 2015) may, however, modify these conclusions. We also discarded the ${ }^{15} \mathrm{~N}+\mathrm{HCNH}^{+}$ and ${ }^{15} \mathrm{~N}+\mathrm{NO}$ exchange reactions through similar arguments. Tentative reaction rate coefficients are also proposed for carbon fractionation reactions involving ${ }^{13} \mathrm{C}^{+}$and ${ }^{13} \mathrm{C}$ with $\mathrm{CN}$ and $\mathrm{C}_{2}$. 
E. Roueff et al.: Isotopic fractionation of carbon, deuterium, and nitrogen: a full chemical study
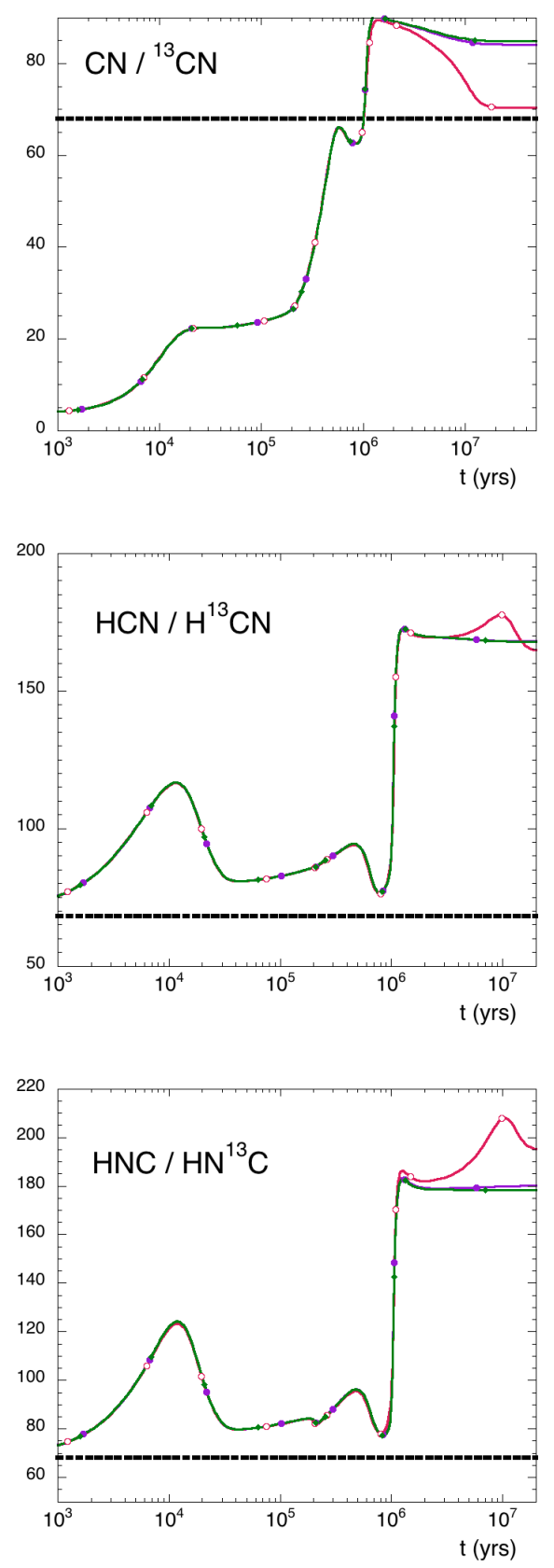
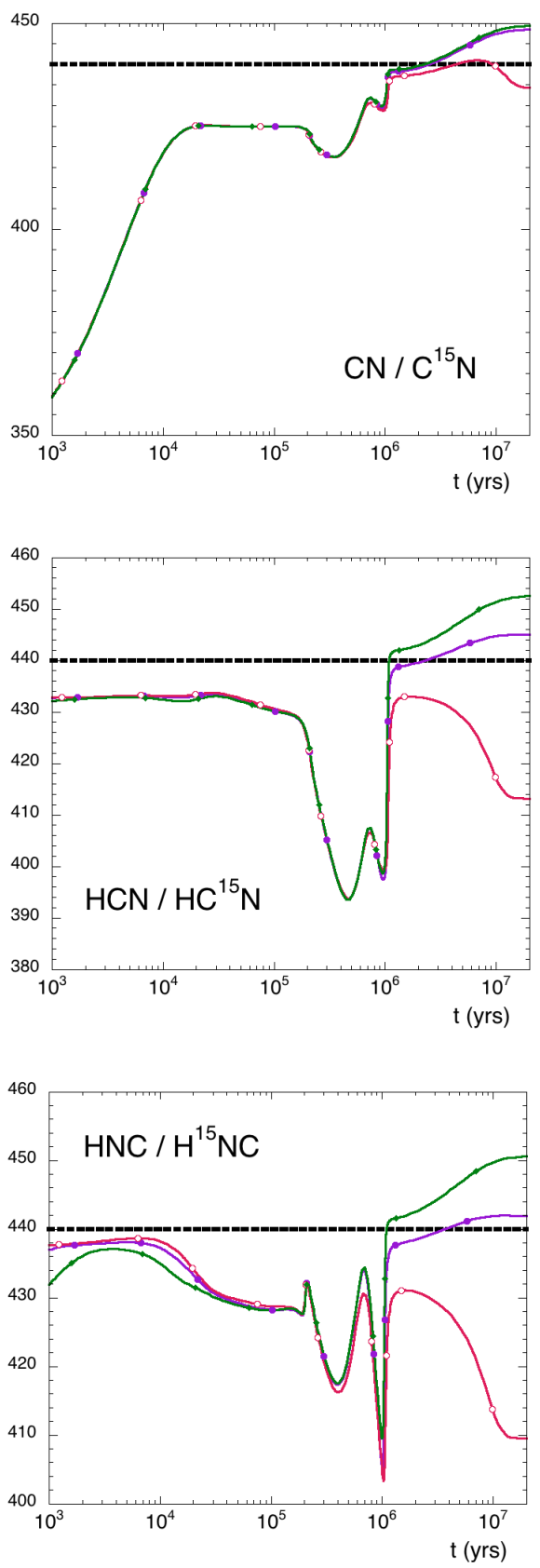

Fig. 8. Time dependence of fractionation ratios of $\mathrm{CN}, \mathrm{HCN}, \mathrm{HNC}$ in model (a) for 3 different OPR values. Black heavy dotted line: elemental ratio; green: $\mathrm{OPR}=10^{-4}$; purple: $\mathrm{OPR}=10^{-3}$; red: $\mathrm{OPR}=10^{-2}$.
Additionally, we explicitly considered the various isotopologues involved in the $\mathrm{N}^{+}+\mathrm{H}_{2}$ reaction, assuming that the energy defect involved in the reactions of ${ }^{14} \mathrm{~N}^{+}$with para- $\mathrm{H}_{2}$ is a "real" endothermicity. This leads to a slight decline in the exponential term when ${ }^{15} \mathrm{~N}^{+}$reacts with $\mathrm{H}_{2}$ and with HD compared to ${ }^{14} \mathrm{~N}^{+}$. This explains satisfactorily that ${ }^{15} \mathrm{NH}_{2} \mathrm{D}$ is found to be more enriched in ${ }^{15} \mathrm{~N}$ than ${ }^{15} \mathrm{NH}_{3}$ in the observations.

Comparison between observations of nitriles and isonitriles and simulated values is much more questionable, because carbon and nitrogen chemistries are interdependent. Observed isotopic ratios are usually large and suffer from large error bars owing to opacity effects in the main isotopologue and difficulties linked to nuclear spin effects. Whereas the various isotopologues follow a similar evolution, the isotopic ratios display significant variations due to slight shifts in the position of the maximum fractional abundances. A reasonable agreement is obtained between the observed ${ }^{13} \mathrm{C} /{ }^{15} \mathrm{~N}$ ratios for most of the species in L134N and Barnard B1 and steady state model values. Our model results show a strong depletion in ${ }^{13} \mathrm{C}$ and a near elemental ratio for ${ }^{14} \mathrm{~N} /{ }^{15} \mathrm{~N}$, whereas observations are usually interpreted by assuming an elemental ratio for ${ }^{13} \mathrm{C}$ containing species, which leads to the incorrect assumption of ${ }^{15} \mathrm{~N}$ enrichment. These considerations undeniably depend on the chosen elemental abundances and, in particular, on the assumed $\mathrm{C} / \mathrm{O}$ ratio. We additionally point out a somewhat unexpected effect of the ortho-to-para ratio of $\mathrm{H}_{2}$, which significantly affects the fractional ionization and, consequently, the level of deuterium fractionation through the respective orders of magnitude of DR rate coefficients of polyatomic molecular ions. The importance of coupling $\mathrm{C}, \mathrm{O}$, and $\mathrm{N}$ chemistries was emphasized.

Acknowledgements. We acknowledge the support of PCMI (Programme National de Physique et Chimie du Milieu Interstellaire). This work has been partially funded by the Agence Nationale de la Recherche (ANR) research project IMOLABS (ANR-13-BS05-0008). 

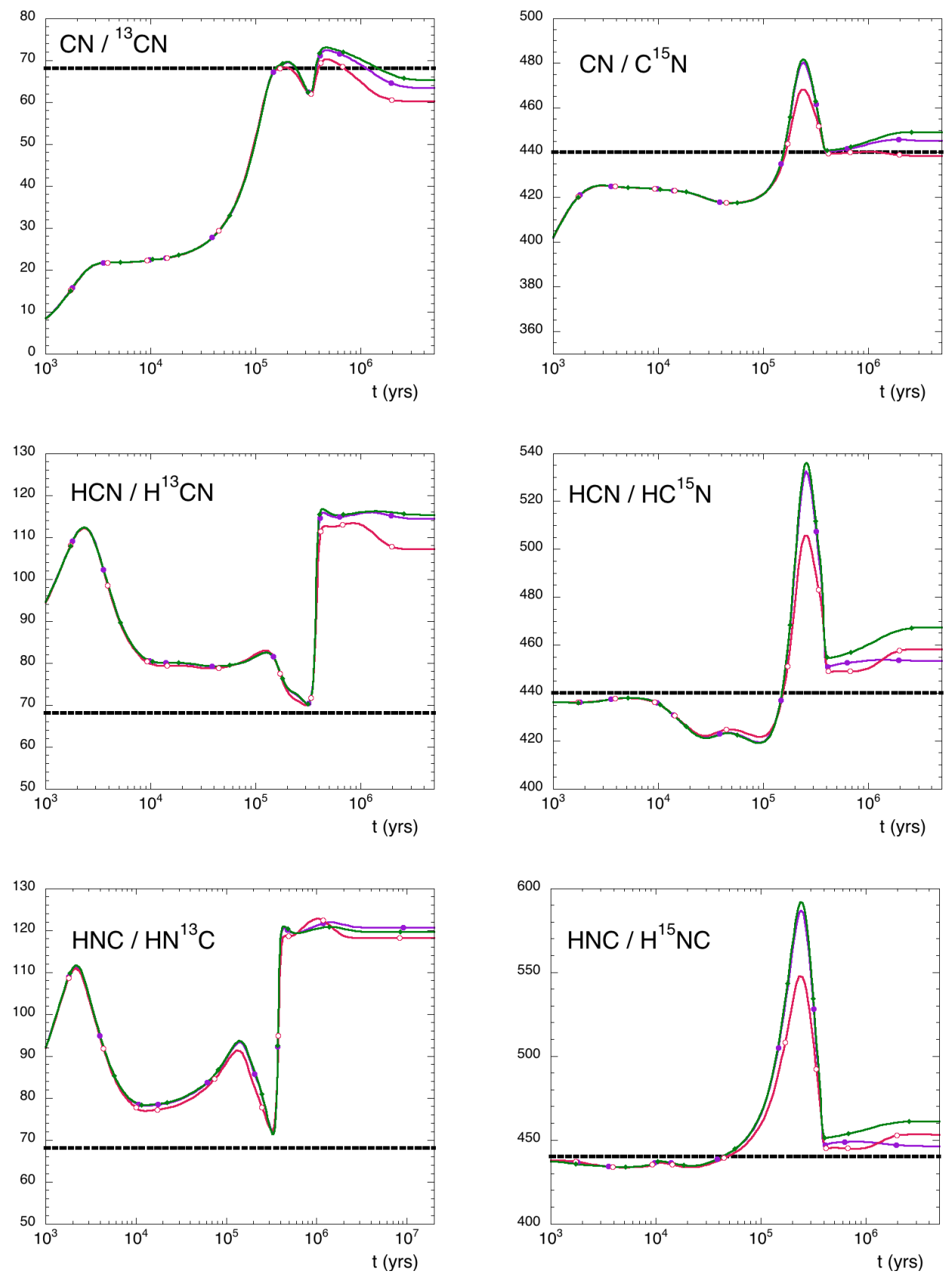

Fig. 9. Time dependence of fractionation ratios of $\mathrm{CN}, \mathrm{HCN}, \mathrm{HNC}$ in model (b) for 3 different OPR values. Black heavy dotted line: elemental ratio; green: $\mathrm{OPR}=10^{-4}$; purple: $\mathrm{OPR}=10^{-3}$; red: $\mathrm{OPR}=10^{-2}$.

\section{References}

Adams, N. G., \& Smith, D. 1981, ApJ, 247, L123 Adande, G. R., \& Ziurys, L. M. 2012, ApJ, 744, 194

Aléon, J. 2010, ApJ, 722, 1342

Anicich, V. G., \& Huntress, Jr., W. T. 1986, ApJS, 62, 553

Anicich, V. G., Huntress, Jr., W. T., \& Futrell, J. H. 1977, Chem. Phys. Lett., 47, 488

Barlow, S. E., \& Dunn, G. H. 1987, Int. J. Mass Spectrometry and Ion Processes, 80,227

Bizzocchi, L., Caselli, P., \& Dore, L. 2010, A\&A, 510, L5

Bizzocchi, L., Caselli, P., Leonardo, E., \& Dore, L. 2013, A\&A, 555, A109

Brites, V., \& Jutier, L. 2012, J. Mol. Spectr., 271, 25

Colin, R. 1989, J. Mol. Spectr., 136, 387

Colin, R., \& Bernath, P. F. 2012, J. Mol. Spectr., 273, 30

Daniel, F., Faure, A., Wiesenfeld, L., et al. 2014, MNRAS, 444, 2544

Danielak, J., Kepa, R., \& Zachwieja, M. 1997, J. Phys. B Atom. Mol. Phys., 30, 4889

Daranlot, J., Hincelin, U., Bergeat, A., et al. 2012, Proc. Nat. Acad. Sci., 109, 10233

Daranlot, J., Hu, X., Xie, C., et al. 2013, Phys. Chem. Chem. Phys. (Incorporating Faraday Transactions), 15, 13888
Dislaire, V., Hily-Blant, P., Faure, A., et al. 2012, A\&A, 537, A20

Dore, L., Bizzocchi, L., Esposti, C. D., \& Tamassia, F. 2011, Mol. Phys., 109, 2191

Faure, A., Hily-Blant, P., Le Gal, R., Rist, C., \& Pineau des Forêts, G. 2013, ApJ, 770, L2

Flower, D. R., Pineau Des Forêts, G., \& Walmsley, C. M. 2006, A\&A, 456, 215

Furuya, K., Aikawa, Y., Sakai, N., \& Yamamoto, S. 2011, ApJ, 731, 38

Gamallo, P., Martínez, R., Sayós, R., \& González, M. 2010, J. Chem. Phys., 132, 144304

Georgievskii, Y., \& Klippenstein, S. J. 2005, J. Chem. Phys., 122, 194103

Gerin, M., Viala, Y., \& Casoli, F. 1993, A\&A, 268, 212

Gerin, M., Marcelino, N., Biver, N., et al. 2009, A\&A, 498, L9

Glassgold, A. E., Huggins, P. J., \& Langer, W. D. 1985, ApJ, 290, 615

Grant Hill, J., Mitrushchenkov, A., Yousaf, K. E., \& Peterson, K. A. 2011, J. Chem. Phys., 135, 144309

Guelachvili, G., de Villeneuve, D., Farrenq, R., Urban, W., \& Verges, J. 1983, J. Mol. Spectr., 98, 64

Henry, A., Le Moal, M. F., Cardinet, P., \& Valentin, A. 1978, J. Mol. Spectr., 70, 18

Herbst, E., Defrees, D. J., Talbi, D., Pauzat, F., \& Koch, W. 1991, J. Chem. Phys., 94,7842 
E. Roueff et al.: Isotopic fractionation of carbon, deuterium, and nitrogen: a full chemical study

Herzberg, G. 1945, Molecular Spectra and Molecular Structure, Vol. 2: Infrared and Raman Spectra of Polyatomic Molecules (New York: Van Nostrand), 372

Herzberg, G. 1989, Molecular Spectra and Molecular Structure, Vol. 1: Spectra of Diatomic Molecules (Malabar: Krieger Publishing Company)

Hily-Blant, P., Bonal, L., Faure, A., \& Quirico, E. 2013a, Icarus, 223, 582

Hily-Blant, P., Pineau des Forêts, G., Faure, A., Le Gal, R., \& Padovani, M. 2013b, A\&A, 557, A65

Hirano, N., \& Liu, F.-c. 2014, ApJ, 789, 50

Huang, X., Valeev, E. F., \& Lee, T. J. 2010, J. Chem. Phys., 133, 244108

Huang, X., Schwenke, D. W., \& Lee, T. J. 2011, J. Chem. Phys., 134, 044321

Ikeda, M., Hirota, T., \& Yamamoto, S. 2002, ApJ, 575, 250

Jensen, P., \& Kraemer, W. P. 1988, J. Mol. Spectr., 129, 216

Langer, W. D., \& Penzias, A. A. 1990, ApJ, 357, L477

Langer, W. D., Graedel, T. E., Frerking, M. A., \& Armentrout, P. B. 1984, ApJ, 277,581

Le Bourlot, J. 1991, A\&A, 242, 235

Le Bourlot, J., Pineau Des Forets, G., Roueff, E., \& Flower, D. R. 1993, A\&A, 267,233

Le Gal, R., Hily-Blant, P., Faure, A., et al. 2014, A\&A, 562, A83

Le Picard, S. D., \& Canosa, A. a. 1998, J. Chem. Soc. Faraday Trans., 94, 2889

Le Roy, R. J., Huang, Y., \& Jary, C. 2006, J. Chem. Phys., 125, 164310

Lique, F., Daniel, F., Pagani, L., \& Feautrier, N. 2015, MNRAS, 446, 1245

Lis, D. C., Wootten, A., Gerin, M., \& Roueff, E. 2010, ApJ, 710, L49

Liszt, H. S. 2007, A\&A, 476, 291

Liszt, H. S., \& Ziurys, L. M. 2012, ApJ, 747, 55

Lohr, L. L. 1998, J. Chem. Phys., 108, 8012

Loison, J.-C., Wakelam, V., \& Hickson, K. M. 2014, MNRAS, 443, 398

Lucas, R., \& Liszt, H. 1998, A\&A, 337, 246

Ma, J., Guo, H., \& Dawes, R. 2012, Phys. Chem. Chem. Phys., 14, 12090

Maki, A. G., \& Mellau, G. C. 2001, J. Mol. Spectr., 206, 47

Maki, A. G., Mellau, G. C., Klee, S., Winnewisser, M., \& Quapp, W. 2000, J. Mol. Spectr., 202, 67

Marquette, J. B., Rebrion, C., \& Rowe, B. R. 1988, J. Chem. Phys., 89, 2041

Martin, J. M. L., Taylor, P. R., \& Lee, T. J. 1993, J. Chem. Phys., 99, 286

Marty, B., Chaussidon, M., Wiens, R. C., Jurewicz, A. J. G., \& Burnett, D. S. 2011, Science, 332, 1533

Mebel, A. M., \& Kaiser, R. I. 2002, ApJ, 564, 787

Mendes, M. B., Buhr, H., Berg, M. H., et al. 2012, ApJ, 746, L8

Milam, S. N., Savage, C., Brewster, M. A., Ziurys, L. M., \& Wyckoff, S. 2005, ApJ, 634, 1126

Milligan, D. B., Fairley, D. A., Freeman, C. G., \& McEwan, M. J. 2000, Int. J. Mass Spectrometry, 202, 351

Mladenović, M., \& Roueff, E. 2014, A\&A, 566, A144
Möllmann, E., Maki, A. G., Winnewisser, M., Winnewisser, B. P., \& Quapp, W. 2002, J. Mol. Spectr., 212, 22

Ohishi, M., Irvine, W. M., \& Kaifu, N. 1992, in Astrochemistry of Cosmic Phenomena, ed. P. D. Singh, IAU Symp., 150, 171

Pagani, L., Roueff, E., \& Lesaffre, P. 2011, ApJ, 739, L35

Pillai, T., Wyrowski, F., Hatchell, J., Gibb, A. G., \& Thompson, M. A. 2007, A\&A, 467, 207

Ram, R. S., \& Bernath, P. F. 2010, J. Mol. Spectr., 260, 115

Ram, R. S., \& Bernath, P. F. 2012, J. Mol. Spectr., 274, 22

Ram, R. S., Wallace, L., \& Bernath, P. F. 2010, J. Mol. Spectr., 263, 82

Rodgers, S. D., \& Charnley, S. B. 2004, MNRAS, 352, 600

Rodgers, S. D., \& Charnley, S. B. 2008a, ApJ, 689, 1448

Rodgers, S. D., \& Charnley, S. B. 2008b, MNRAS, 385, L48

Roueff, E., Lis, D. C., van der Tak, F. F. S., Gerin, M., \& Goldsmith, P. F. 2005 A\&A, 438, 585

Sakai, N., Saruwatari, O., Sakai, T., Takano, S., \& Yamamoto, S. 2010, A\&A, 512, A31

Sakai, N., Takano, S., Sakai, T., et al. 2013, J. Phys. Chem. A, 117, 9831

Sattelmeyer, K. 2004, Chem. Phys. Lett., 383, 266

Savage, C., Apponi, A. J., Ziurys, L. M., \& Wyckoff, S. 2002, ApJ, 578, 211

Smith, D., \& Adams, N. G. 1980, ApJ, 242, 424

Taatjes, C. A. 1997, J. Chem. Phys., 106, 1786

Terzieva, R., \& Herbst, E. 2000, MNRAS, 317, 563

Tiné, S., Roueff, E., Falgarone, E., Gerin, M., \& Pineau des Forêts, G. 2000, A\&A, 356, 1039

Vigren, E., Zhaunerchyk, V., Hamberg, M., et al. 2012, ApJ, 757, 34

Visser, R., van Dishoeck, E. F., \& Black, J. H. 2009, A\&A, 503, 323

Wakelam, V., Smith, I. W. M., Loison, J.-C., et al. 2013, unpublished [arXiv: 1310.4350 ]

Wampfler, S. F., Jorgensen, J. K., Bizzarro, M., \& Bisschop, S. E. 2014, A\&A, 572, A24

Wang, Q., Ding, Y.-H., \& Sun, C.-C. 2005, Chem. Phys. Chem., 6, 431

Wang, Q., Ding, Y.-H., \& Sun, C.-C. 2006, Chem. Phys. Chem., 7, 710

Watson, W. D., Anicich, V. G., \& Huntress, Jr., W. T. 1976, ApJ, 205, L165

Wirström, E. S., Charnley, S. B., Cordiner, M. A., \& Milam, S. N. 2012, ApJ, 757, L11

Zachwieja, M. 1995, J. Mol. Spectr., 170, 285

Zachwieja, M. 1997, J. Mol. Spectr., 182, 18

Zachwieja, M., Szajna, W., \& Hakalla, R. 2012, J. Mol. Spectr., 275, 53

Zhang, X.-N., Shi, D.-H., Sun, J.-F., \& Zhu, Z.-L. 2011, Chin. Phys. B, 20, 043105

Zhao, Y., \& Truhlar, D. G. 2008, Theor. Chem. Accounts, 120, 215

Zymak, I., Hejduk, M., Mulin, D., et al. 2013, ApJ, 768, 86 


\section{Appendix A: Exchange reactions}

We discuss below the reactions displayed in Table 1.

$-\mathbf{N}^{15} \mathbf{N}+\mathbf{N}_{2} \mathbf{H}^{+} \rightleftharpoons \mathbf{N}^{15} \mathbf{N H}^{+}+\mathbf{N}_{2}$

$\mathbf{N}^{15} \mathbf{N}+\mathbf{N}_{2} \mathbf{H}^{+} \rightleftharpoons{ }^{15} \mathbf{N N H}^{+}+\mathbf{N}_{2}$

These reactions have been studied experimentally by Adams \& Smith (1981) at $80 \mathrm{~K}$ without differentiating between $\mathrm{N}^{15} \mathrm{NH}^{+}$and ${ }^{15} \mathrm{NNH}^{+}$. The total rate is $4.6 \times 10^{-10} \mathrm{~cm}^{3} \mathrm{~s}^{-1}$. We thus take half this value for the forward reaction rate constant, considering the symmetry factor, and we assume no barrier for these rapid reactions.

We also introduce the $\mathbf{N}^{15} \mathbf{N}+{ }^{15} \mathbf{N} \mathbf{N H}^{+} \rightleftharpoons \mathbf{N}^{15} \mathbf{N H}^{+}+\mathbf{N}^{15} \mathbf{N}$ reaction for completeness.

$-{ }^{15} \mathbf{N}^{+}+\mathbf{N}_{2} \rightleftharpoons{ }^{14} \mathbf{N}^{+}+\mathbf{N}^{15} \mathbf{N}$

This reaction involves adduct formation. The numerical constant is computed to reproduce the experimental value of Anicich et al. (1977) at room temperature.

$-{ }^{15} \mathbf{N}+\mathrm{CNC}^{+} \rightleftharpoons \mathrm{C}^{15} \mathrm{NC}^{+}+{ }^{14} \mathbf{N}$

No information is available for this reaction. The bimolecular exit channels ${ }^{12} \mathrm{C}^{+}+\mathrm{NCN}$ and $\mathrm{C}_{2}{ }^{+} / \mathrm{N}_{2}$ are both endothermic by 170 and $76 \mathrm{~kJ} / \mathrm{mol}$, respectively. We performed DFT calculations (at the M06-2X/cc-pVTZ level) to explore the possibility of isotopic exchange. Direct $\mathrm{N}$ exchange is impossible because it would require simultaneous bond formation, rearrangement, and bond breaking. However, isotopic exchange could take place through adduct formation. No barrier was found in the entrance channel for $\mathrm{NCNC}^{+}$formation (exothermic by $167 \mathrm{~kJ} / \mathrm{mol}$ ). The most favorable $\mathrm{NCNC}^{+}$ isomerization pathway is cyclic. However, the position of the $\mathrm{c}-\mathrm{NC}(\mathrm{N}) \mathrm{C}^{+}$transition state (TS) is highly uncertain and is found to be below the entrance channel at M06-2X/cc-pVQZ level $(-14 \mathrm{~kJ} / \mathrm{mol})$ but slightly above the entrance level at the RCCSD(T)-F12/aug-cc-pVTZ level (+19 kJ/mol). In any case, the TS position is close to the entrance level so that the $\mathrm{NCNC}^{+}$back dissociation is favored at room temperature. Isotopic exchange may, however, be enhanced at low temperature and may become the main exit channel. Considering a $T^{-1}$ temperature dependence of the adduct lifetime, we tentatively suggest $k_{\mathrm{f}}=3.8 \times 10^{-12} \times(T / 300)^{-1} \mathrm{~cm}^{3} \mathrm{~s}^{-1}$.

$-{ }^{15} \mathbf{N}^{+}+{ }^{14} \mathbf{N O} \rightleftharpoons{ }^{14} \mathbf{N}^{+}+\mathbf{N}^{15} \mathbf{N}$

Terzieva \& Herbst (2000) estimated the value of this rate coefficient from the difference between the Langevin rate and the other measured exothermic reactions reported below:

$$
\begin{array}{rll}
{ }^{15} \mathrm{~N}^{+}+{ }^{14} \mathrm{NO} & \rightarrow{ }^{15} \mathrm{~N}+\mathrm{NO}^{+}\left(k_{1}\right) & \Delta H_{\mathrm{r}}=-509 \mathrm{~kJ} / \mathrm{mol} \\
& \rightarrow{ }^{15} \mathrm{NN}^{+}+\mathrm{O}\left(k_{2}\right) & \Delta H_{\mathrm{r}}=-213 \mathrm{~kJ} / \mathrm{mol} \\
& \rightarrow \mathrm{N}^{15} \mathrm{~N}+\mathrm{O}^{+} & \Delta H_{\mathrm{r}}=-402 \mathrm{~kJ} / \mathrm{mol} \\
& \rightarrow{ }^{14} \mathrm{~N}^{+}+{ }^{15} \mathrm{NO} & \Delta H_{\mathrm{r}}=-0.2 \mathrm{~kJ} / \mathrm{mol}
\end{array}
$$

$k_{1}=5.0 \times 10^{-10} \mathrm{~cm}^{3} \mathrm{~s}^{-1}$ and $k_{2}=5.0 \times 10^{-11} \mathrm{~cm}^{3} \mathrm{~s}^{-1}$. No data are available for the two other reactions. We find a barrier for $\mathrm{NON}^{+}$adduct formation $(261 \mathrm{~kJ} / \mathrm{mol}$ at the M06-2X/cc-pVTZ level) and neglect this exchange reaction. $-{ }^{15} \mathbf{N}+\mathbf{N}_{2} \mathbf{H}^{+} \rightleftharpoons{ }^{14} \mathbf{N}+\mathbf{N}^{15} \mathbf{N H}^{+} /{ }^{15} \mathbf{N N H}{ }^{+}$

No information is available for these reactions, which were reported as crucial by Rodgers \& Charnley (2008b). We performed DFT calculations (at the M06-2X/cc-pVTZ level) which showed that isotopic exchange through the addition elimination mechanism is impossible as the $\mathrm{NN}(\mathrm{H}) \mathrm{N}^{+}$ and $\mathrm{NNNH}^{+}$ions are metastable, respectively 73 and $332 \mathrm{~kJ} / \mathrm{mole}$ above the ${ }^{14} \mathrm{~N}+\mathrm{N}_{2} \mathrm{H}^{+}$energy. Figure A.1 displays the various possibilities. In addition, direct nitrogen exchange through $\mathrm{NN}(\mathrm{H}) \ldots \mathrm{N}^{+} \rightarrow \mathrm{N} \ldots \mathrm{N}(\mathrm{H}) \mathrm{N}^{+}$presents a barrier equal to $+87 \mathrm{~kJ} / \mathrm{mol}$. We did not find any $\mathrm{N}_{3} \mathrm{H}^{+}$ configuration with an energy lower than that of the reactants. We then neglect this reaction.

$-{ }^{15} \mathbf{N N H}^{+}+\mathbf{H} \rightleftharpoons \mathbf{H}+\mathbf{N}^{15} \mathbf{N H}^{+}$

Following a similar suggestion for explaining abundance anomalies of the ${ }^{13} \mathrm{C}$ species of $\mathrm{CCH}$ (Sakai et al. 2010), we consider the above reaction, for which no information is available. We performed various DFT calculations at the M06-2X/cc-pVTZ level. The $\mathrm{HNNH}^{+}$ion is $109 \mathrm{~kJ} / \mathrm{mole}$ more stable than $\mathrm{H}+\mathrm{N}_{2} \mathrm{H}^{+}$, but the addition reaction shows a barrier of $+12 \mathrm{~kJ} / \mathrm{mole}$. The intramolecular isomerization ${ }^{15} \mathrm{NNH}^{+} \rightarrow \mathrm{N}^{15} \mathrm{NH}^{+}$also displays a barrier of $+172 \mathrm{~kJ} / \mathrm{mole}$. Then direct isomerization through tunneling is expected to be very slow, and we neglect that reaction ${ }^{2}$.

$-{ }^{15} \mathbf{N}+\mathbf{H C N H}^{+} \rightleftharpoons{ }^{14} \mathbf{N}+\mathbf{H C}^{15} \mathbf{N H}^{+}$

This reaction was also suggested by Terzieva \& Herbst (2000) despite the lack of any relevant information. We performed DFT calculations to explore the possibility of isotopic exchange as shown in Fig. A.2. Direct N exchange is found to be impossible because it requires simultaneous bond formation, rearrangement, and bond breaking so that isotopic exchange involves adduct formation. Attack by atomic nitrogen on either side of the $\mathrm{HCNH}^{+}$molecular ion leads to a metastable system through high-energy transition states. We did not consider transition states leading to $\mathrm{N}$ addition on the $\mathrm{C}=\mathrm{N}$ bond of $\mathrm{HCNH}^{+}$, nor did we examine $\mathrm{N}$ insertion into the $\mathrm{N}-\mathrm{H}$ or $\mathrm{C}-\mathrm{H}$ bonds, since all these pathways led to species located above the reagent energy level. We did not find any $\mathrm{CN}_{2} \mathrm{H}_{2}{ }^{+}$species lying below the reagent energy level, and we consider that this reaction cannot take place.

$-{ }^{15} \mathbf{N}+\mathbf{C N} \rightleftharpoons{ }^{14} \mathbf{N}+\mathbf{C}^{15} \mathbf{N}$

The $\mathrm{N}\left({ }^{4} \mathrm{~S}^{o}\right)+\mathrm{CN}\left({ }^{2} \Sigma^{+}\right)$reaction leads to ${ }^{3,5} \Sigma^{-}$surfaces in $\mathrm{C}_{\infty V}$ symmetry and ${ }^{3,5} \mathrm{~A}^{\prime \prime}$ surfaces in Cs symmetry. The quintuplet surface is repulsive at the MRCI+Q/aug-ccpVTZ level, and the ${ }^{5} \mathrm{NCN}$ intermediate is above the $\mathrm{N}+\mathrm{CN}$ level. Considering only the triplet surface, the only barrierless reaction is attack on the carbon atom that leads to the ground state ${ }^{3} \mathrm{NCN}$ intermediate (Daranlot et al. 2012; Ma et al. 2012). The main exit channel is $\mathrm{C}+\mathrm{N}_{2}$ after isomerization of the NCN intermediate through a tight TS, and then back dissociation may be important and isotope exchange possible. In the nominal model, we neglect this reaction, but some tests were performed to estimate its potential role. The upper limit of the isotope exchange rate constant is equal to the capture rate constant minus the $\mathrm{N}+\mathrm{CN} \rightarrow \mathrm{C}+\mathrm{N}_{2}$ rate constant. That value is notably lower than the capture one at low temperature. We thus propose the upper limit value of $2.0 \times$ $10^{-10} \times(T / 300)^{1 / 6} \frac{1}{1+\exp (-22.9 / T)} \mathrm{cm}^{3} \mathrm{~s}^{-1}$ for the forward rate constant.

$-{ }^{15} \mathbf{N}+\mathbf{C}_{2} \mathbf{N} \rightleftharpoons{ }^{14} \mathbf{N}+\mathbf{C}_{2}{ }^{15} \mathbf{N}$

The $\mathrm{N}\left({ }^{4} \mathrm{~S}\right)+\mathrm{C}_{2} \mathrm{~N}\left({ }^{2} \Pi\right)$ reaction leads to ${ }^{3,5} \Pi$ surfaces in $\mathrm{C}_{\infty V}$ symmetry and ${ }^{3,5} \mathrm{~A}^{\prime}+{ }^{3,5} \mathrm{~A}^{\prime \prime}$ surfaces in Cs symmetry. Figure A.3 displays the positions of the state energies linked to $\mathrm{N}+\mathrm{C}_{2} \mathrm{~N}$, which are calculated at the MRCI+Q/aug-ccpVTZ level:10 e- in $10 \mathrm{OM}$ with the geometry fully optimized at the CASCCF level or 14 e- in 14 OM for the CASCCF and 14e- in 12 OM for the MRCI calculation with non relaxed geometry. The triplet surface pathway leads to a NCCN adduct in a triplet state, corresponding to an excited state of the very stable NCCN linear molecule, located

2 We note in addition that $\mathrm{N}_{2} \mathrm{H}^{+}$formation from $\mathrm{N}_{2}+\mathrm{H}_{3}{ }^{+}$is exothermic by only $72 \mathrm{~kJ} / \mathrm{mole}$, so that any ${ }^{15} \mathrm{NNH}^{+}$produced will not isomerize into $\mathrm{N}^{15} \mathrm{NH}^{+}$and vice versa. 


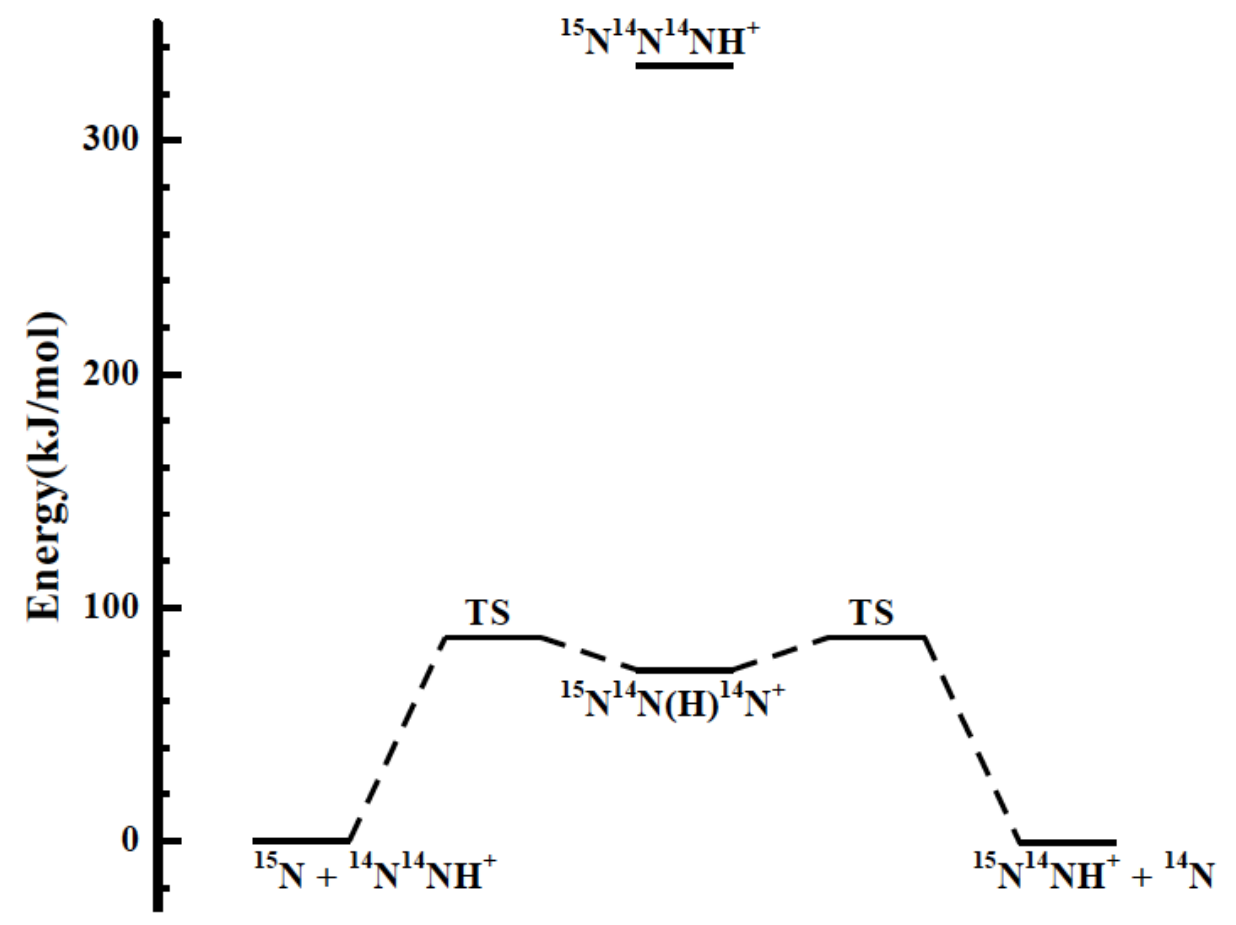

Fig. A.1. Energy diagram of the $\mathrm{NNNH}^{+}$system.



Fig. A.2. Energy diagram of the $\mathrm{HCNNH}^{+}$system.

$-393 \mathrm{~kJ} / \mathrm{mol}$ below the $\mathrm{N}\left({ }^{4} \mathrm{~S}\right)+\mathrm{C}_{2} \mathrm{~N}\left({ }^{2} \Pi\right)$ level. No barrier is present in the entrance valley so that this $\mathrm{NCCN}$ adduct very likely leads to $\mathrm{CN}$ (in a doublet state) $+\mathrm{CN}$ (in a doublet state) products. The occurrence of a small exit barrier cannot be excluded, but its energy should be much lower than that of the ${ }^{14} \mathrm{~N}+\mathrm{C}_{2}{ }^{15} \mathrm{~N}$ entrance channel. Triplet surfaces thus cannot lead to isotopic exchanges. However, the quintuplet surface deserves specific attention because the $\operatorname{NCCN}\left({ }^{5} \Sigma^{+}\right)$ adduct is found at an energy of $-183 \mathrm{~kJ} / \mathrm{mol}$ below that of the $\mathrm{N}\left({ }^{4} \mathrm{~S}\right)+\mathrm{C}_{2} \mathrm{~N}\left({ }^{2} \Pi\right)$ level (at the MRCI+Q, RCCSD(T) 


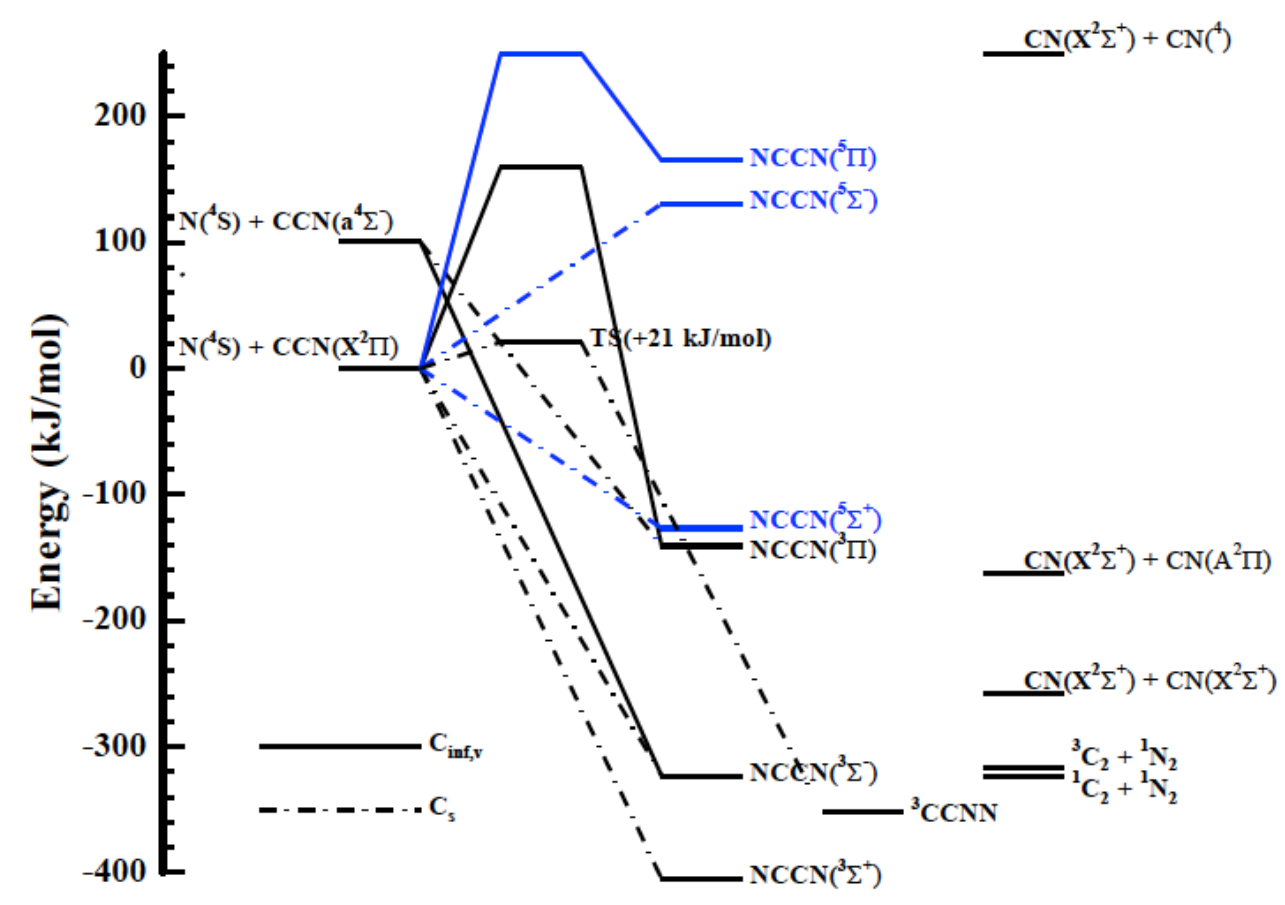

Fig. A.3. Energy diagram of the CCNN system.

and DFT level of calculations). However, no exothermic bimolecular exit channel is available on this quintuplet surface. We thus conclude that the quintuplet surface could lead to isotopic exchange and finally consider the two following possibilities for this reaction involving the very reactive $C_{2} \mathrm{~N}$ radical (Wang et al. 2005, 2006), i.e. the triplet channel,

$$
\begin{aligned}
{ }^{15} \mathrm{~N}\left({ }^{4} S\right) & +\mathrm{C}_{2} \mathrm{~N}\left({ }^{2} \Pi\right) \rightarrow{ }^{15} \mathrm{NCCN}\left({ }^{3} \Sigma^{+},{ }^{3} \Sigma^{-}\right) \\
& \rightarrow \mathrm{C}^{15} \mathrm{~N}\left({ }^{2} \Sigma^{+},{ }^{2} \Pi\right)+\mathrm{CN}\left({ }^{2} \Sigma^{+},{ }^{2} \Pi\right)
\end{aligned}
$$

and the quintuplet channel,

$$
\begin{aligned}
& { }^{15} \mathrm{~N}\left({ }^{4} S\right)+\mathrm{C}_{2} \mathrm{~N}\left({ }^{2} \Pi\right) \rightarrow{ }^{15} \mathrm{NCCN}\left({ }^{5} \Sigma^{+}\right) \rightarrow{ }^{15} \mathrm{~N}\left({ }^{4} S\right)+\mathrm{C}_{2} \mathrm{~N}\left({ }^{2} \Pi\right) \\
& { }^{15} \mathrm{~N}\left({ }^{4} S\right)+\mathrm{C}_{2} \mathrm{~N}\left({ }^{2} \Pi\right) \rightarrow{ }^{15} \mathrm{NCCN}\left({ }^{5} \Sigma^{+}\right) \rightarrow{ }^{14} \mathrm{~N}\left({ }^{4} S\right)+\mathrm{C}_{2}{ }^{15} \mathrm{~N}\left({ }^{2} \Pi\right) . \\
& -{ }^{15} \mathbf{N}+{ }^{14} \mathbf{N O} \rightleftharpoons{ }^{14} \mathbf{N}+{ }^{15} \mathrm{NO}
\end{aligned}
$$

There is a barrier for NON adduct formation. The isotope exchange rate is calculated to be very low (Gamallo et al. 2010) since the main exit channel is $\mathrm{N}_{2}+\mathrm{O}$. Moreover, the quintuplet surfaces are repulsive. We neglect this reaction.

$-{ }^{13} \mathbf{C}^{+}+\mathbf{C O} \rightleftharpoons{ }^{12} \mathbf{C}^{+}+{ }^{13} \mathbf{C O}$

This reaction was first mentioned by Watson et al. (1976) and has been experimentally studied in detail by Smith \& Adams (1980) in the 80-500 K temperature range. Their data can be fitted (Liszt 2007). We introduce a new formula allowing us to describe the full temperature range with a single formula.

$-{ }^{13} \mathrm{CO}+\mathrm{HCO}^{+} \rightleftharpoons \mathrm{CO}+\mathrm{H}^{13} \mathrm{CO}^{+}$

This reaction has also been studied experimentally by Smith \& Adams (1980). The exothermicity of the reaction has been reported as $9 \mathrm{~K}$ by Langer et al. (1984) from theoretical studies, whereas Smith \& Adams (1980) proposed a value of $12 \pm 5 \mathrm{~K}$. However, a later study by Lohr (1998) leads to a value of 17.4 K. Mladenović \& Roueff (2014) have reconsidered this reaction and confirm the value of Lohr (1998). We include this exothermicity value in the present work. Experimental points are fitted through a power law as given in Table 1.

\section{$-{ }^{13} \mathbf{C}^{+}+\mathbf{C N} \rightleftharpoons{ }^{12} \mathbf{C}^{+}+{ }^{13} \mathbf{C N}$}

There are no bimolecular exit channels for this reaction and two different pathways lead to isotopic exchange. In a direct reaction, ${ }^{13} \mathrm{C}^{+}+\mathrm{NC} \rightarrow{ }^{13} \mathrm{CNC}^{+} \rightarrow{ }^{13} \mathrm{CN}+{ }^{12} \mathrm{C}^{+}$, whereas the indirect pathway involves ${ }^{13} \mathrm{C}^{+}+\mathrm{CN} \rightarrow{ }^{13} \mathrm{CCN}^{+}$ $\rightarrow{ }^{13} \mathrm{CN}+{ }^{12} \mathrm{C}^{+}$. There is no barrier in the entrance valley for both cases at the M06-2X/cc-pVTZ level. Moreover, the cyclic transition state from $\mathrm{CCN}^{+}$and $\mathrm{CNC}^{+}$is located at $-436 \mathrm{~kJ} / \mathrm{mol}$ below the reactant energy, leading to fast isomerization. The corresponding capture rate constant is $3.82 \times 10^{-9} \times(T / 300)^{-0.40}$.

$-{ }^{13} \mathbf{C}+\mathbf{C N} \rightleftharpoons{ }^{12} \mathbf{C}+{ }^{13} \mathbf{C N}$

In a similar way to the ionic case, no exothermic bimolecular exit channels are available for this reaction and two reaction pathways occur for possible isotopic exchange. ${ }^{13} \mathrm{C}+\mathrm{NC} \rightarrow{ }^{13} \mathrm{CNC} \rightarrow{ }^{13} \mathrm{CN}+{ }^{12} \mathrm{C}$ holds for the direct process, and ${ }^{13} \mathrm{C}+\mathrm{CN} \rightarrow{ }^{13} \mathrm{CCN} \rightarrow \mathrm{c}-{ }^{13} \mathrm{CNC} \rightarrow{ }^{13} \mathrm{CN}+{ }^{12} \mathrm{C}$ describe the indirect exchange mechanism. No barrier is found in the entrance channel, and the transition state from CCN to $\mathrm{c}-\mathrm{CCN}$ is low $(-298 \mathrm{~kJ} / \mathrm{mol}$ below the reactant energy), in good agreement with Mebel \& Kaiser (2002) so that isomerization is expected to be fast. The capture rate is computed as $3.0 \times 10^{-10} \mathrm{~cm}^{3} \mathrm{~s}^{-1}$.

$-{ }^{13} \mathbf{C}+\mathbf{H C N} \rightleftharpoons{ }^{12} \mathbf{C}+\mathbf{H}^{13} \mathbf{C N}$

There are no exothermic bimolecular exit channels for this reaction and no barrier for $\mathrm{HCNC}$ formation, but isotopic exchange requires isomerization through a TS located close to the reactant level, involving a TS located at $-16 \mathrm{~kJ} / \mathrm{mol}$ at the M06-2X/cc-pVQZ level but $+34 \mathrm{~kJ} / \mathrm{mol}$ at the RCCSD(T)F12-aug-cc-pVQZ level. Calculation of the rate constant for exchange is complex and similar to the ${ }^{15} \mathrm{~N}+\mathrm{CNC}^{+}$case. We neglect this reaction in the nominal model.

$-{ }^{13} \mathbf{C}+\mathbf{C}_{2} \rightleftharpoons{ }^{12} \mathbf{C}+{ }^{13} \mathbf{C C}$

There are no exothermic product channels for this reaction, and there is very likely to be no barrier. The capture rate constant is equal to $3.0 \times 10^{-10} \mathrm{~cm}^{3} \mathrm{~s}^{-1}$. 
Table B.1. Atomic masses in amu from NIST.

\begin{tabular}{lc}
\hline \hline Atom & Mass \\
\hline $\mathrm{H}$ & 1.00782503207 \\
$\mathrm{D}$ & 2.0141017778 \\
$\mathrm{~N}$ & 14.003074004 \\
${ }^{15} \mathrm{~N}$ & 15.000108898 \\
$\mathrm{C}$ & 12.00 \\
${ }^{13} \mathrm{C}$ & 13.003354838 \\
$\mathrm{O}$ & 15.9949146196 \\
${ }^{18} \mathrm{O}$ & 17.9991610 \\
$\mathrm{e}$ & 0.00054858 \\
\hline
\end{tabular}

\section{$-{ }^{13} \mathrm{CH}+\mathrm{CO} \rightleftharpoons{ }^{13} \mathrm{CO}+\mathrm{CH}$}

This reaction could be an additional possibility for enhancing ${ }^{13} \mathrm{CO}$ because no barrier has been found in the entrance valley (Le Picard \& Canosa 1998). The high-pressure $\mathrm{CH}+$ $\mathrm{CO} \rightarrow \mathrm{HCCO}$ association reaction rate constant is equal to $3 \times 10^{-11} \times(T / 300)^{-0.9}$ between 53 and $294 \mathrm{~K}$. The exchange rate has been measured to be $\sim \times 10^{-12}$ (Taatjes 1997) at room temperature. This value represents $1 \%$ of the association reaction rate constant at high pressure, which is explained by a transition state localized at $6 \mathrm{~kJ} / \mathrm{mole}$ above the reactants energy as computed at the M06-2X/cc-pVTZ level, in good agreement with Sattelmeyer (2004). We do not include this reaction in our models given the high TS which should make this exchange process negligible at low temperature.

\section{Appendix B: ZPE values}

We revisit the ZPE values in light of several recent studies. We recall in Table B.1 the atomic masses of various isotopes that may be used to derive spectroscopic constants of isotopic molecules, as found in basic molecular spectroscopy textbooks (Herzberg 1945, 1989). We only refer to the first-order expansion terms for the purpose of computing ZPEs.

\section{B.1. Diatomic molecules}

For diatomic molecules, energy levels are expressed as a Dunham expansion or equivalently as a sum of harmonic + anharmonicity correction factors. The following expression is obtained for the ZPE, corresponding to $v=0$ :

$Z P E=\frac{1}{2} Y_{10}+\frac{1}{4} Y_{20}=\frac{1}{2} \omega_{0}-\frac{1}{4} \omega_{\mathrm{e}} x_{\mathrm{e}}$

where $\omega_{0}$ is the harmonic contribution of the vibrational frequency and $\omega_{\mathrm{e}} x_{\mathrm{e}}$ represents the anharmonic contribution. The reduced mass $\mu$ dependence of $\omega_{0}$ and $\omega_{\mathrm{e}} x_{\mathrm{e}}$ are $1 / \sqrt{\mu}$ and $1 / \mu$, respectively. The label computed in Table B.2 indicates the use
Table B.2. Spectroscopic constants of diatomic molecules in $\mathrm{cm}^{-1}$ and differences of ZPE with respect to the main isotopologue.

\begin{tabular}{lccccc}
\hline \hline Molecule & Ref. & $\omega_{\mathrm{e}}$ & $\omega_{\mathrm{e}} x_{\mathrm{e}}$ & $\mathrm{ZPE}$ & $\Delta(\mathrm{ZPE})(\mathrm{K})$ \\
\hline $\mathrm{N}_{2}$ & $(1)$ & 2358.53 & 14.30 & 1175.7 & - \\
$\mathrm{N}^{15} \mathrm{~N}$ & $(1)$ & 2319.01 & 13.83 & 1156.05 & 28.3 \\
${ }^{15} \mathrm{~N}_{2}$ & $(1)$ & 2278.80 & 13.35 & 1136.06 & 57.0 \\
$\mathrm{NH}$ & $(2)$ & 3282.2 & 78.3 & 1621.5 & - \\
${ }^{15} \mathrm{NH}$ & computed & 3274.9 & 77.95 & 1617.9 & 5.2 \\
$\mathrm{ND}$ & $(3)$ & 2399.0 & 42.0 & 1189.5 & 621.6 \\
${ }^{15} \mathrm{ND}$ & computed & 2389.0 & 41.6 & 1183.6 & 630 \\
$\mathrm{NH}^{+}$ & $(4)$ & 3047.58 & 72.19 & 1505.7 & \\
${ }^{15} \mathrm{NH}^{+}$ & $(4)$ & 3040.77 & 71.87 & 1502.4 & 4.8 \\
$\mathrm{ND}^{+}$ & $(4)$ & 2226.93 & 38.55 & 1103.8 & 578 \\
${ }^{15} \mathrm{ND}$ & computed & 2217.60 & 38.23 & 1099.2 & 585 \\
$\mathrm{CN}^{+3} \mathrm{CN}$ & $(5)$ & 2068.68 & 13.12 & 1031.1 & - \\
${ }^{15} \mathrm{~N}$ & $(6)$ & 2025.25 & 12.57 & 1009.5 & 31.1 \\
${ }^{14} \mathrm{NO}$ & $(8)$ & 2036.70 & 12.70 & 1015.2 & 22.9 \\
${ }^{15} \mathrm{NO}$ & $(9)$ & 1804.11 & 14.08 & 948.5 & - \\
$\mathrm{C}_{2}$ & $(10)$ & 1853.5 & 13.585 & 931.7 & 24.3 \\
${ }^{13} \mathrm{CC}$ & $(10)$ & 1817.3 & 12.1 & 905.61 & 26.4 \\
$\mathrm{CO}$ & $(11)$ & 2169.8 & 13.3 & 1081.6 & - \\
${ }^{13} \mathrm{CO}$ & $(11)$ & 2121.4 & 12.7 & 1057.5 & 34.7 \\
$\mathrm{CH}$ & $(12)$ & 2860.75 & 64.44 & 1414.3 & - \\
${ }^{13} \mathrm{CH}$ & $(13)$ & 2852.15 & 64.04 & 1410.1 & 6.0 \\
$\mathrm{CD}$ & $(14)$ & 2101.05 & 34.7 & 1042.1 & 535.5 \\
\hline
\end{tabular}

References. (1) Le Roy et al. (2006); (2) Ram \& Bernath (2010); (3) Dore et al. (2011); (4) Colin (1989); (5) Ram et al. (2010); (6) Ram \& Bernath (2012); (7) Colin \& Bernath (2012); (8) Henry et al. (1978); (9) Danielak et al. (1997); (10) Zhang et al. (2011); (11) Guelachvili et al. (1983); (12) Zachwieja (1995); (13) Zachwieja (1997); (14) Zachwieja et al. (2012).

of this property to compute the spectroscopic constants, in the absence of other information.

\section{B.2. Polyatomic molecules}

For polyatomic molecules, the following expression extends the diatomic formulae where the different vibrational degrees of freedom are included:

$G_{0}=\sum_{i} \omega_{i} \frac{d_{i}}{2}+\sum_{i} \sum_{j} x_{i j} \frac{d_{i}}{2} \frac{d_{j}}{2}$

where $\omega_{i}$ refers to the harmonic frequencies, $d_{i}$ is the corresponding degeneracy, and $x_{i j}$ stands for the anharmonic terms. The sum is performed over the number of vibrational modes. In the case of polyatomic linear molecules, the number of vibrational modes is $3 \mathrm{~N}-5$, whereas it is $3 \mathrm{~N}-6$ in the general case where $\mathrm{N}$ is the number of nuclei in the molecule. 
A\&A 576, A99 (2015)

Table B.3. Spectroscopic constants of triatomic molecules in $\mathrm{cm}^{-1}$ and differences of ZPE with respect to the main isotopologue.

\begin{tabular}{lcccccc}
\hline \hline Molecule & \multirow{2}{*}{ Ref. } & $\omega_{1}$ & $\omega_{2}$ & $\omega_{3}$ & ZPE & $\Delta(\mathrm{ZPE})(\mathrm{K})$ \\
symmetry & & $\Sigma^{+}$ & $\Pi$ & $\Sigma^{+}$ & & \\
\hline $\mathrm{HCN}$ & $(1)$ & 3443.1 & 727.0 & 2127.4 & 3512.25 & - \\
$\mathrm{H}^{13} \mathrm{CN}$ & $(1)$ & 3424.0 & 720.6 & 2093.0 & 3478.6 & 48.4 \\
$\mathrm{HC}^{15} \mathrm{~N}$ & $(1)$ & 3441.7 & 725.9 & 2094.0 & 3493.75 & 26.6 \\
$\mathrm{H}^{13} \mathrm{C}^{15} \mathrm{~N}$ & $(1)$ & 3422.6 & 719.5 & 2058.6 & 3460.1 & 75.0 \\
$\mathrm{DCN}$ & $(2)$ & 2702.5 & 579.7 & 1952.3 & 2883.9 & 904.1 \\
$\mathrm{CCN}$ & $(3)$ & 1967.2 & 322.2 & 1058.3 & 1794.20 & - \\
${ }^{13} \mathrm{CCN}$ & $(3)$ & & & & 1778.19 & 23.0 \\
$\mathrm{C}^{13} \mathrm{CN}$ & $(3)$ & & & & 1761.11 & 47.6 \\
$\mathrm{CC}{ }^{15} \mathrm{~N}$ & $(3)$ & & & & 1775.65 & 26.7 \\
$\mathrm{HNC}$ & $(4)$ & 3819.9 & 463.8 & 2064.3 & 3369.9 & - \\
$\mathrm{HN}^{13} \mathrm{C}$ & $(4)$ & - & 463.5 & - & & \\
$\mathrm{H}^{15} \mathrm{NC}^{\mathrm{N}}$ & $(4)$ & - & 461.5 & - & & \\
$\mathrm{N}_{2} \mathrm{H}^{+}$ & $(5)$ & 3398.6 & 695.5 & 2297.7 & 3508.6 & - \\
${ }^{15} \mathrm{NNH}^{+}$ & $(5)$ & 3396.5 & 694.4 & 2259.3 & 3487.5 & 30.4 \\
$\mathrm{~N}^{15} \mathrm{NH}^{+}$ & $(5)$ & 3382.4 & 690.7 & 2268.7 & 3481.8 & 38.5 \\
${ }^{15} \mathrm{~N}_{2} \mathrm{H}^{+}$ & $(5)$ & 3380.7 & 699.6 & 2229.3 & 3460.4 & 69.3 \\
$\mathrm{~N}_{2} \mathrm{D}^{+}$ & $(5)$ & 2719.8 & 550.4 & 2065.9 & 2916.2 & 852 \\
$\mathrm{~N}^{15} \mathrm{ND}^{+}$ & $(5)$ & 2680.4 & 544.4 & 2058.8 & 2888.4 & 40.0 \\
${ }^{15} \mathrm{NND}^{+}$ & $(5)$ & 2703.8 & 549.0 & 2041.0 & 2895.2 & 30.2 \\
$\mathrm{CNC}^{+}$ & $(6)$ & 1335 & 165 & 2040 & 1852.5 & - \\
$\mathrm{C}^{15} \mathrm{NC}^{+}$ & $(6)$ & 1334 & 161 & 1997 & 1826 & 38.1 \\
$\mathrm{HCO}^{+}$ & $(7),(9)$ & 3229.6 & 832.5 & 2195.8 & 3524.60 & - \\
$\mathrm{H}^{13} \mathrm{CO}^{+}$ & $(8),(9)$ & 3206.1 & 824.9 & 2160.6 & 3488.24 & 52.3 \\
$\mathrm{DCO}^{+}$ & $(7),(9)$ & 2645.9 & 666.5 & 1928.0 & 2944.22 & 835.1 \\
\hline
\end{tabular}

References. (1) Maki et al. (2000); (2) Möllmann et al. (2002); (3) Grant Hill et al. (2011), priv. comm.; (4) Maki \& Mellau (2001); (5) Huang et al. (2010); (6) Jensen \& Kraemer (1988); (7) Martin et al. (1993); (8) Lee (priv. comm.), based on second-order vibrational perturbation theory using a quartic force field determined at the $\operatorname{CSSD}(\mathrm{T}) / \mathrm{cc}-\mathrm{pVTZ}$ level of electronic structure theory, as in (7); (9) ZPEs are from Mladenović \& Roueff (2014).

Table B.4. Spectroscopic constants of tetratomic nitrogen molecules in $\mathrm{cm}^{-1}$ and differences of ZPE with respect to the main isotopologue.

\begin{tabular}{lcccccccc}
\hline \hline $\begin{array}{l}\text { Molecule } \\
\text { symmetry }\end{array}$ & Ref. & $\omega_{1}$ & $\omega_{2}$ & $\omega_{3}$ & $\omega_{4}$ & $\omega_{5}$ & ZPE & $\Delta(\mathrm{ZPE})(\mathrm{K})$ \\
\hline $\mathrm{HCNH}^{+}$ & $(1)$ & 3484.2 & 3187.3 & 2159.9 & 804.8 & 649.4 & 5987.3 & - \\
$\mathrm{H}^{13} \mathrm{CNH}^{+}$ & $(1)$ & 3479.5 & 3170.1 & 2126.1 & 799.8 & 647.4 & 5952.0 & 50.8 \\
$\mathrm{HC}^{15} \mathrm{NH}^{+}$ & $(2)$ & 3469.3 & 3187.1 & 2133.3 & 804.7 & 645.1 & 5961.5 & 37.1 \\
$\mathrm{HCND}^{+}$ & $(1)$ & 3221.9 & 2681.1 & 2025.9 & 794.3 & 513.1 & 5364.2 & 896.5 \\
$\mathrm{DCNH}^{+}$ & $(1)$ & 3474.0 & 2601.0 & 1934.8 & 664.7 & 622.8 & 5388.0 & 862.3 \\
\hline Molecule & Ref. & $\omega_{1}$ & $\omega_{2}$ & $\omega_{3}$ & $\omega_{4}$ & & $\mathrm{ZPE}$ & $\Delta(\mathrm{ZPE})(\mathrm{K})$ \\
symmetry & & $\mathrm{A}_{1}$ & $\mathrm{~A}_{1}$ & $\mathrm{E}$ & $\mathrm{E}$ & & & \\
\hline $\mathrm{NH}_{3}$ & $(3)$ & 3336.1 & 932.4 & 3443.6 & 1626.3 & & 7429.2 & - \\
${ }^{15} \mathrm{NH}_{3}$ & $(3)$ & 3333.3 & 928.5 & 3435.1 & 1623.2 & & 7413.0 & 23.3 \\
\hline
\end{tabular}

References. (1) Brites \& Jutier (2012); (2) Brites, priv. comm.; (3) Huang et al. (2011). 